\title{
Experimental study of the hydrodynamic behaviour of slug flow in a horizontal pipeline
}

\author{
M. Abdulkadir*1, 2, V. Hernandez-Perez ${ }^{3}$, I. S. Lowndes ${ }^{3}$, B. J. Azzopardi ${ }^{3}$ and E. Sam-Mbomah ${ }^{2}$ \\ ${ }^{1}$ Department of Chemical Engineering, Federal University of Technology, Minna, Niger State, Nigeria \\ ${ }^{2}$ Petroleum Engineering Department, African University of Science and Technology (AUST), Abuja, Nigeria \\ ${ }^{3}$ Process and Environmental Engineering Research Division, Faculty of Engineering, University of Nottingham \\ University Park, Nottingham, NG7 2RD, United Kingdom \\ *Email of the corresponding author: mukhau@futminna.edu.ng
}

\begin{abstract}
Despite the research efforts in the last decades, the dynamic behaviour of gas-liquid two-phase flows remains a challenging topic. This is due to the growing demand within the petroleum, process and nuclear industries. In particular, data on the behaviour of these flows in more industry relevant fluids are limited. This paper presents a summary of the experimental results on the hydrodynamic behaviour of slug flow using airsilicone oil mixture in a horizontal $67 \mathrm{~mm}$ internal diameter pipeline. A series of slug flow regime experiments were performed for a range of injected air superficial velocities $\left(0.29\right.$ to $\left.1.4 \mathrm{~ms}^{-1}\right)$ and the liquid flows with superficial velocities of between 0.05 to $0.47 \mathrm{~ms}^{-1}$. The translational Taylor bubble velocity and slug frequency were measured using two pairs of Electrical Capacitance Tomography (ECT) probes. The expected linear dependence of the translational Taylor bubble velocity on the mixture superficial velocity was confirmed. Pressure drop was measured using a differential pressure (dp) transducer cell. The void fractions in the liquid slugs and Taylor bubbles and slug and Taylor bubble lengths parameters were obtained from the processed data. The average total lengths of the observed slugs were of the order of 8 to 46 pipe diameters. The dimensionless Taylor bubble length is concluded to increase as the gas superficial velocity increases. The average slug frequency was observed to increase as the liquid superficial velocity increases but on the other hand was concluded to be fairly weakly dependent on the gas superficial velocity. The measured translational Taylor bubble velocities, void fractions in the liquid, and slug frequencies are presented and compared to data predicted by empirical models available in the literature. A comparative analysis of this and the previously published experimental data sets confirms good agreement.
\end{abstract}

Key words: ECT, Taylor bubble, liquid slug, slug unit, frequency, void fraction 


\subsection{Introduction:}

The determination of the multiphase flow regimes that may exist within pipelines is a key factor to the development of efficient oil and gas production systems. As oil and gas reserves are being depleted in developed fields, activity is shifting to harsher and less accessible environments. As offshore production moves into deeper waters farther offshore, the cost of constructing and operating fixed platforms with separation facilities becomes increasingly challenging. An alternative solution is to utilize subsea production systems which entail minimum offshore processing. The adoption of this method requires the simultaneous transport of produced fluids to land-based separation facilities, with minimal offshore treatment to reduce the undesirable effects as corrosion, wax and hydrates formation. Thus, an accurate prediction of the multiphase flow characteristics that may be experienced within these pipelines is therefore required to effect the safe and economic design and operation of these transportation systems.

Slug flows are the most prevalent pattern experienced in multiphase transportation pipelines due to the long transport distances involved, normal production rates, and large pipeline diameters and uneven elevation profiles experienced in multiphase transportation pipelines. It is also one of the most complex flow patterns due to the irregular nature of the phase distributions.

The presence of long, high density, fast moving liquid slugs within transport pipelines can cause significant variations in oil and gas flow rates entering downstream processing facilities, and result in mechanical damage to pipeline connections and supports (Bagci [1]). Therefore, the prediction of the maximum possible slug length is of particular importance in the design of the pipeline connections and infrastructure and all downstream processing units. 
The proper design of multiphase pipelines and downstream processing facilities requires a thorough understanding of the behaviour of slug flow in pipelines. For this reason, it is of major interest within many industrial processes, including: upstream and downstream oil and gas processes, geothermal production of steam, chemical plants and refineries, and the handling and transport of cryogenic fluids [1-2].

From a practical point of view, slug flow is frequently encountered in pipelines over a wide range of intermediate flow rates: for horizontal and vertical flows. For designing these systems, reliable techniques are needed for predicting gas-liquid slug flow characteristics in horizontal pipelines. However, reports on the study of the behaviour of these slugs in more industry relevant fluids are limited. For that reason, it is imperative to study the behaviour of slug flow in great detail for the optimal, efficient and safe design and operation of two-phase gas-liquid slug flow systems.

In this work, an analysis of the ECT data enabled the observed slug flows to be characterized. This was achieved by the measurement of the instantaneous distribution of the flow phases over the cross-section of the pipe. The use of two sets of circumferential ring sensor electrodes, located $89 \mathrm{~mm}$ apart (also known as twin-plane sensors), enabled the determination of the translational velocities of the observed Taylor gas bubbles and liquid slugs.

\subsection{Background:}

Slug flow in horizontal pipes has received significant attention in the past mainly to provide design engineers with the means to avoid this flow pattern. Several investigators have developed flow pattern maps and models to characterize the various flow patterns that may be 
adopted by two-phase oil and gas flow mixtures, for instance references [2], [3-6] and [7-14]. Unlike the case of vertical two-phase flow there is fairly more flexibility in designing for horizontal pipes. Although the slug flow regime has been included in experimental studies, specific details of flow phenomena for this regime are sparse. In addition, much of the slug flow data reported in the literature are of limited usefulness for developing a slug flow correlation, mainly due to the use of air-water as the operating fluid.

[2] carried out a series of experiments to study slug flows created within a horizontal pipeline test loop with an internal diameter of $50 \mathrm{~mm}$. The passage of the slugs was measured by the use of circumferential conductance probes. They found that the translational velocity of the Taylor bubbles is not only dependent on Froude number, but is also significantly affected by the distance from the entrance of pipeline for higher mixture velocities. They also proposed that the average liquid slug length is relatively insensitive to the gas and liquid flow rates at the higher mixture velocities. However, in the lower mixture velocity range, the mean liquid slug length is concluded to be affected by the mixture velocity. Finally, they concluded that the mean slug frequency clearly increases as the liquid superficial velocity increases but is weakly dependant on the gas superficial velocity.

Abdulkadir et al. [15] carried out a detailed experimental investigation to study the hydrodynamics of slug flows in a $67 \mathrm{~mm}$ internal diameter vertical riser. They employed electrical capacitance tomography (ECT) transducer to determine: the translational velocities of the Taylor bubbles and liquid slugs, the slug frequencies, the lengths of the Taylor bubbles and the liquid slugs, the void fractions within the Taylor bubbles and liquid slugs and the liquid film thickness. They also used a differential pressure (DP) transducer cell to measure the pressure drops experienced along the length of the riser. 
This paper details the results of studies conducted to extend these initial investigations, [15], to consider horizontal flows. A detailed description of these experimental investigations is presented below.

\subsubsection{Slug flow characterization:}

Hubbard and Dukler [3] model serves as the theoretical benchmark to our current understanding of slug flow patterns. A brief synopsis of the alternative methods to determine the characteristics of slug flows is presented, below:

\section{Slug velocity}

A slug may be characterized by the determination of the interfacial velocities; the slug front and the bubble front. The bubble front translational velocity, $U_{B F}$, is often approximated by the form suggested by [4].

$U_{B F}=1.2 U_{S}+U_{D}$

Where, $U_{s}$ is the average velocity of the liquid in the slug. For homogeneous, no-slip flow in the slug body, $U_{s}=U_{M}$. Therefore, the term $1.2 U_{M}$ is approximately equal to the maximum velocity that the liquid in the slug may achieve. The drift velocity, $U_{D}$, in equation (1) is the relative velocity between the maximum gas velocity in the bubble, $U_{B F}$, and the maximum velocity of the liquid in the slug, $1.2 U_{s}$.

As reported whilst the drift velocity is clearly non-zero for inclined flows [3], and [5-6], proposed that the drift velocity, $U_{D}=0$, for horizontal flows. In contrast, other investigators [4] and [16-17], observed significant drift velocities in horizontal pipes. Weber [7] considered a force balance on the nose of a stationary bubble to explain the absence of drift velocities in 
horizontal pipes. The solution of this force balance reveals that for a horizontal pipe, open to the atmosphere at one end and closed at the other, there is a critical Eotvos number, $E o_{D}$, below which liquid will not drain i.e. no any drift will occur. [7] also proposed the following correlation for the drift velocity in horizontal pipes:

$\frac{U_{D}}{\sqrt{g D}}=0.54-0.76 E o_{D}^{-0.56}$

Where,

$$
E o=\frac{\rho_{L} g D^{2}}{\sigma}
$$

and

$\rho_{L}$ is the liquid density, $D$ is the internal pipe diameter, $\sigma$ is liquid surface tension and $\mathrm{g}$ is the acceleration due to gravity

Bendiksen [8] presented the formula to calculate the bubble drift velocity in inclined pipes:

$U_{D}=\left(U_{D}\right)_{\text {horizontal }} \cos (\phi)+\left(U_{D}\right)_{\text {vertical }} \sin (\phi)$

where,

$\phi$ is the pipe inclination angle

Davies and Taylor [9] showed that, the bubble drift velocity in vertical tube is:

$U_{D_{\text {vertical }}}=0.35 \sqrt{g D}$

For horizontal pipe, [10] proposed the following relation:

$U_{D_{\text {horizonal }}}=0.54 \sqrt{g D}$

Equation (2) should be used in place of equation (6) for cases when the Eotvos number is small (i.e. for small diameter pipes or very viscous fluids). 


\section{Liquid holdup in the liquid slug body}

One of the primary variables required to characterize slug flows is the liquid holdup in the slug body, $H_{s}$. Gregory et al. [11] measured the slug body holdup for the flow of air and light refined oil in horizontal pipes with internal diameters of $25.8 \mathrm{~mm}$ and $51.2 \mathrm{~mm}$. They proposed a correlation which relates $H_{s}$ to the mixture superficial velocity, $U_{M}$. This is expressed as equation (7), which is currently the most commonly used method to adequately describe slug liquid holdup behaviour.

$$
H_{s}=\frac{1}{1+\left(\frac{U_{M}}{8.66}\right)^{1.39}}
$$

However, available data from the literature show that slug holdup is not a unique function of $U_{M}$, but appears to vary to some degree with operational and geometric conditions. In addition, visual observations suggest that at some flow rates, a homogeneous mixture is not achieved in the slug body. Instead, stratification of liquid holdup occurs with less aeration near the bottom of the pipe than at the top.

Malnes [18] included fluid properties (liquid density and surface tension), and proposed the following correlation:

$$
H_{s}=1-\frac{U_{M}}{\left[83\left(\frac{g \sigma}{\rho_{L}}\right)^{1 / 4}+U_{M}\right]}
$$

Marcano et al. [12] considered sixty-two slug flow cases produced by a various combinations of increasing gas and liquid flow rates flowing around a $420 \mathrm{~m}$ long horizontal flow loop of $78 \mathrm{~mm}$ internal diameter pipe. Based on the analysis of their experimental results, they formulated the following correlation to describe the observed slug body holdup: 


$$
H_{s}=\frac{1}{1.001+0.0179 U_{M}+0.0011 U_{M}{ }^{2}}
$$

Gomez et al. [13] analysed the data collated from the results of experimental studies conducted by a number of investigators who considered slug flows within pipes with internal diameters of between 51 to $203 \mathrm{~mm}$, set at inclinations of between $0-90^{\circ}$, and operating at pressures of between 1.5 to 20 bar. This analysis identified a clear dependency between the angle of the pipe inclination, the slug Reynolds number $(R e)$, and the slug void fraction. They proposed the following correlation expressed as equation (10).

$$
H_{s}=e^{-(0.45 \theta+C \mathrm{Re})}, 0 \leq \theta_{R} \leq \frac{\pi}{2}
$$

Where,

the pipe angle $\theta$ is in radian, the coefficient $\mathrm{C}=2.48 \times 10^{-6}$; where the slug Reynolds number is defined as:

$$
\operatorname{Re}_{L}=\frac{\rho_{L} U_{M} D}{\mu_{L}}
$$

\section{Slug length}

The average lengths of liquid slugs that have been experimentally observed in horizontal pipes according to [14] are in the range of between 12-40 pipe diameters.

The determination of the slug length (or frequency) is a key characterization parameter within almost all of the proposed slug flow models. According to [19], the prediction of the slug length is perhaps the most difficult parameter to estimate. Slug length has been found to be strongly dependent on the diameter of the carrier pipeline. This can complicate the 
application of correlation models obtained on small diameter test facilities to scale-up of larger field scale facilities.

For small diameter horizontal pipes, Barnea and Taitel [20] showed that the average slug length was 1.5 times the minimum stable slug length, whereas the maximum slug length was 3 times the minimum stable slug length. [21] modelled minimum stable slug lengths of up to 20 D. A comparative analysis of the model solutions with the available experimental data concluded that the actual expected slug lengths were of the order of 1-2 times the minimum length.

A series of investigators [20-23] have reported stable slug lengths of between 15-40 pipe diameters in horizontal and slightly inclined pipes. All of these studies concluded that the slug length is fairly insensitive to the gas and liquid flow rates, and depend principally on the pipe diameter.

\section{Slug frequency}

[5] defined the slug frequency, $f_{s}$ as the average number of slug units passing a given point in the system over a unit of time. And despite the availability of many slug frequency data reported in the literature, it is still one of the least reliably estimated parameters. This is due to the statistical nature of slug flow patterns, and the frequency parameter reflects the intermittency of the flow. However, due to its inclusion as a closure relation in many slug flow models, it is important to accurately predict this parameter. The variation in slug frequency observed depends on whether if the flow is developing or fully developed.

Table 1 presents a summary of the slug frequency models considered in this work. 
Table 1: Summary of fully developed slug frequency models

\begin{tabular}{|c|c|c|c|}
\hline Model & $\begin{array}{c}\text { Pipe } \\
\text { diameter } \\
(\mathrm{mm})\end{array}$ & Fluid & Slug frequency \\
\hline [6] & 42 & Air-Water & $f_{s}=0.0434\left[\frac{U_{S L}}{U_{M}}\left(\frac{2.02}{D}+\frac{U_{M}^{2}}{g D}\right)\right]^{1.02}$ \\
\hline [14] & 19 & $\mathrm{CO}_{2}-$ Water & $f_{s}=0.0226\left[\frac{U_{S L}}{g D}\left(\frac{19.75}{U_{M}}+U_{M}\right)\right]^{1.2}$ \\
\hline [23] & 52.9 and 90 & Air-Water & $f_{s}=\frac{0.088}{g D}\left(U_{S L}+1.5\right)^{2}$ \\
\hline [24] & 45 & $\mathrm{CO}_{2}$-Water & $f_{s}=0.0226\left[\frac{U_{S L}}{g D}\left(\frac{2.02}{D}+\frac{U_{M}{ }^{2}}{g D}\right)\right]^{1.2}$ \\
\hline [25] & 306 & Air-Water & $f_{s}=\frac{U_{S L}}{D}\left(0.00759 U_{M}+0.01\right)$ \\
\hline [26] & 25 to 203 & $\begin{array}{l}\text { Air-Water } \\
\text { Air-Oil }\end{array}$ & $f_{s}=0.0226\left[\frac{U_{S L}}{g D}\left(\frac{19.75}{U_{M}}+U_{M}\right)\right]^{1.2}[0.836+2.75 \operatorname{Sin} \theta](17)$ \\
\hline
\end{tabular}

It is clear from the results of the analysis and discussion of the experimental data of the gasliquid studies presented above that there are many parameters that influence the multiphase flow phenomena observed. To replicate the conditions that may result in the onset of slug flows in more industry relevant fluids; experiments were conducted to investigate air and 
silicone oil slug flows in a horizontal pipeline. This paper therefore summarises the results of an experimental data to determine the range of the physical parameters that characterize the horizontal slug flow phenomena observed.

\section{Experimental facility:}

The experiments described in this paper were carried out on an inclinable pipe flow rig within the Chemical Engineering Laboratories at the University of Nottingham. Figure 1 shows a schematic diagram of the experimental facility. This rig has been employed for a series of earlier published two-phase flow studies by [5] and [27-29]. The experimental test section of the facility consists of a $6 \mathrm{~m}$ length, $0.067 \mathrm{~m}$ internal diameter transparent acrylic pipe which allows for the visualization and measurement of the development of the injected flows over the length of the test section. The test pipe section may be rotated on the rig to allow it to lie at any inclination angle of between -5 to $90^{\circ}$ to the horizontal. For the experiments reported in this paper the rig test pipe section was mounted as a horizontal pipe (an inclination of $0^{\circ}$ to the horizontal) as shown in Figure 2.

The rig was charged with air-silicone oil mixture to study the flow regimes created by the circulation of various air-oil mixtures created by the controlled pumped circulation of the oil from the reservoir and the injection of compressed air at the base of the inclined riser pipe. The experiments were all performed at an ambient laboratory temperature of approximately $20^{\circ} \mathrm{C}$. The resultant flow patterns created across the range of air injection-silicone oil circulation flow rates studied were measured using electrical capacitance tomography (ECT). The measurements were made at an acquisition frequency of $200 \mathrm{~Hz}$ over a period of 60 seconds for each experimental run. In this study, a ring of electrodes were placed around the circumference of the horizontal pipe at a given height above the injection portals at the bottom of the $6 \mathrm{~m}$ horizontal pipe section. This enabled the measurement of the instantaneous 
distribution of the flow phases over the cross-section of the pipe. The use of two such circumferential rings of sensor electrodes, located at a specified distance apart (also known as twin-plane sensors), enabled the determination of the translational velocity of any observed Taylor bubbles and associated liquid slugs. The twin-plane ECT sensors were placed at a distance of 4.4 and $4.489 \mathrm{~m}$ upstream of the air-silicone oil mixer injection portal located at the base of the horizontal pipeline. A more detailed technical description may be found in [15].

In order to measure the pressure drop, a differential pressure (dp) transducer cell (Rosemount 1151 smart model) with a range of $0-37.4 \mathrm{kPa}$ and an output voltage of $1-5 \mathrm{~V}$ was mounted on the pipe to record the pressure drop along the horizontal pipeline flow test section. The exact axial locations of the tappings are $4.5 \mathrm{~m}$ and $5.36 \mathrm{~m}(67$ and 80 pipe diameters, respectively) from the bottom of the test pipe flow section. Thus, the pressure drop using DP cell was measured simultaneously together with void fraction using ECT. The output of the DP cell was recorded through a computer using LABVIEW 7 software (National Instruments), and was taken at a sampling frequency of $1000 \mathrm{~Hz}$ over 60 seconds for each run.

The experiment was repeated two times to check measurement repeatability. The average standard deviation of the data was $\pm 2 \%$.

The physical properties of the air-silicone oil system and the values of the dimensionless numbers, Eo, $N_{f}$ and $M o$ are presented in Table 2. The measurement uncertainties determined are presented in Table 3. 


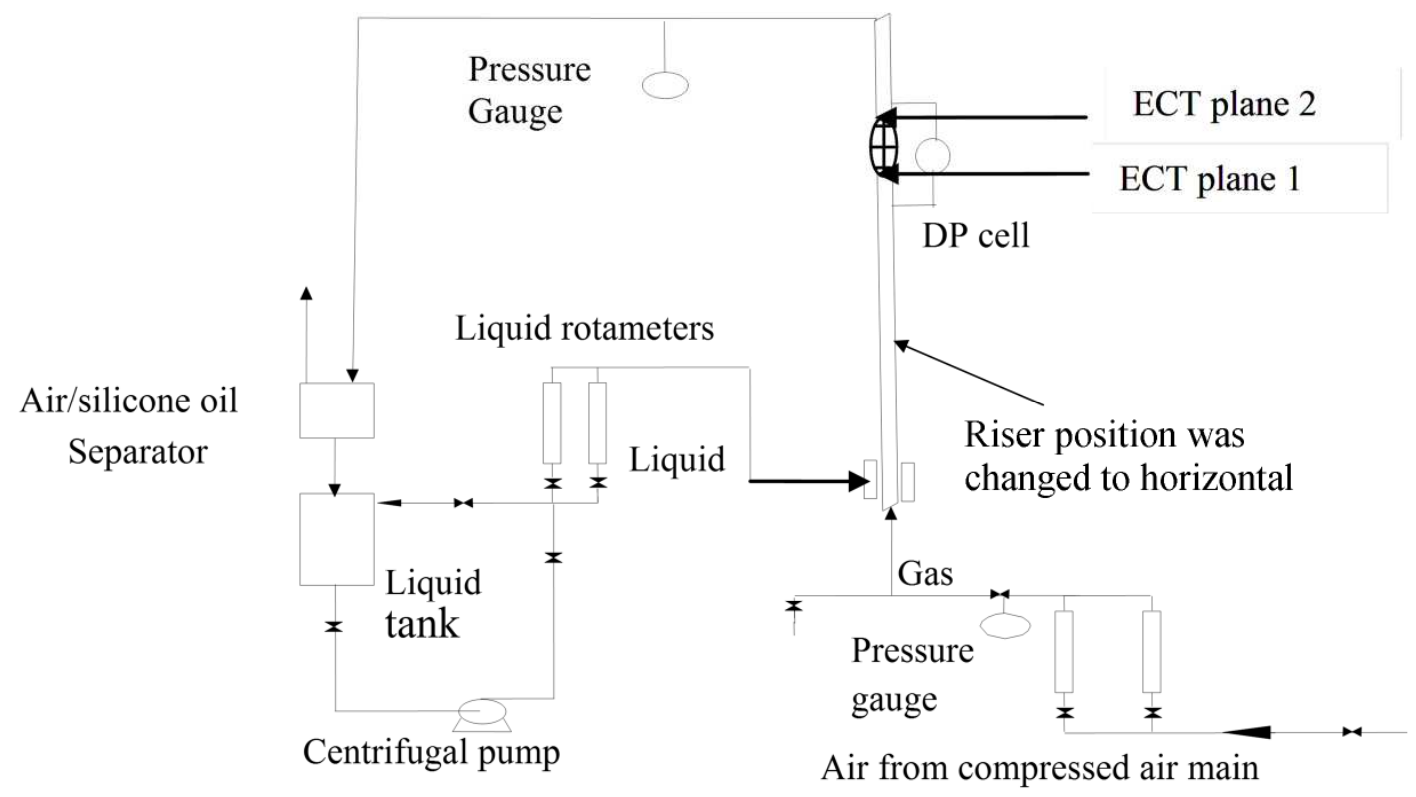

Figure 1 A schematic diagram of the experimental riser rig inclined to be become a horizontal pipeline as shown in Figure 2. The physical measurements recorded on this rig were used to determine parameters that could subsequently be used to characterize the flow regime observed within the horizontal pipeline section when the flow rates of both the silicone oil and the air streams were varied.

Figure 2: Picture of the experimental rig in this study.

Table 2: Properties of the fluids and dimensionless numbers at 1 bar and at the operating temperature of $20^{\circ} \mathrm{C}$

\begin{tabular}{llll}
\hline Fluid & Density $\left(\mathbf{k g m}^{-3}\right)$ & Viscosity $\left(\mathbf{k g m}^{-\mathbf{1}} \mathbf{s}^{-\mathbf{1}}\right)$ & Surface tension $\left(\mathbf{N m}^{-\mathbf{1}}\right)$ \\
\hline Air & 1.18 & 0.000018 & \\
\hline Silicone oil & 900 & 0.0053 & 0.02 \\
\hline Dimensionless numbers & & & \\
\hline Eotvos number & $E O=1981.67$ & & \\
\hline $\begin{array}{l}\text { Dimensionless } \\
\text { viscosity }\end{array}$ & inverse & $N_{f}=9311.72$ & \\
\hline Morton's number & $M o=1.035 \times 10^{-6}$ &
\end{tabular}

Table 3: Measurement uncertainties

\begin{tabular}{ll}
\hline Measurement & Uncertainty range
\end{tabular}




\begin{tabular}{ll}
\hline Temperature $\left({ }^{\circ} \mathrm{C}\right)$ & \pm 0.5 \\
\hline Liquid superficial velocity $\left(\mathrm{ms}^{-1}\right)$ & $\pm 10 \%$ \\
\hline Gas superficial velocity $\left(\mathrm{ms}^{-1}\right)$ & $\pm 0.5-5 \%$ \\
\hline Void fraction & $\pm 10 \%$ of the reading \\
\hline Pressure drop & \pm 0.44 of scale \\
\hline
\end{tabular}

\subsection{Gas-liquid mixing section:}

The mixing device used in this work is made from Polyvinyl chloride (PVC) pipe as shown in Figure 3. The silicone oil enters the mixing chamber from one side and flows around a perforated cylinder through which the air is introduced from the bottom of the mixing chamber directly into the two-phase stream through a porous wall section which has 100 holes of $3 \mathrm{~mm}$ internal diameter orifices. This arrangement ensures that the gas and liquid flows were well mixed at the entry to the test section. The inlet volumetric flow rates of the liquid and air were determined by a set of rotameters located above a set of valves on the two inlets feed flow pipes.

Figure 3: Air-silicone oil mixing section

\section{Results and discussion:}

Khatib and Richardson [30] and [31] proposed that twin peaked probability density function (PDFs) of recorded void fractions represent slug flow as shown in Figure 4. The low void fraction peak corresponds to a liquid slug while the high void fraction peak represents a Taylor bubble. Following this classification of the recorded PDFs of void fraction, it is determined that slug flows are created within the horizontal pipeline for liquid superficial 
velocities of between 0.05 to $0.47 \mathrm{~ms}^{-1}$ and gas superficial velocities of between 0.29 to 1.42 $\mathrm{ms}^{-1}$. This is also shown on Shoham [32]'s flow pattern map, Figure 5.

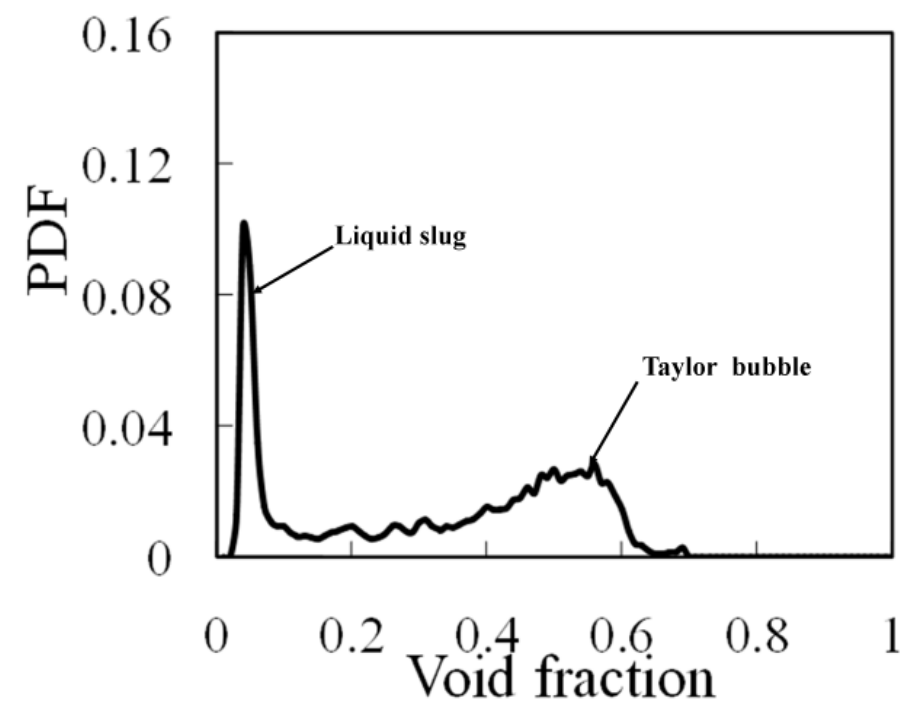

Figure 4: A typical PDF of void fraction. Liquid superficial velocity $=0.19 \mathrm{~ms}^{-1}$ and gas superficial velocity $=$ $0.95 \mathrm{~ms}^{-1}$

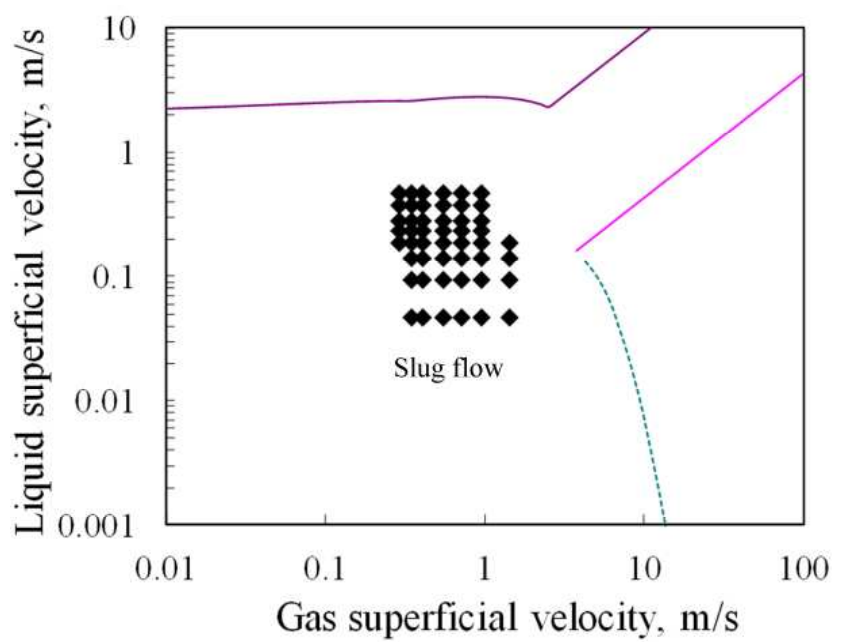

Figure 5: Shoham [32]'s flow pattern map showing experimental data points. All experimental conditions lie in the slug flow region.

The PDF according to [15] was determined by counting the number of data points in bins of width 0.01 centred on void fractions from $0.005,0.015 \ldots . .0 .995$, and then dividing each sum by the total number of data points. This method identifies the dominant void fractions which are observed at each flow condition. 
An analysis of the recorded time series of void fraction enables the determination of the: translational Taylor bubble velocity, slug frequency, lengths of liquid slug, Taylor bubble and slug unit, void fraction within the liquid slug and Taylor bubble.

\subsection{Validation (Testing) of ECT Data:}

In this study, the ECT measurement transducers were used to give detailed information about air-silicone oil flows whilst the wire mesh sensor (WMS) provided a check on the void fraction measurement accuracy. A detailed description of WMS technology is provided by da Silva et al. [33]. The capacitance WMS, placed at $4.92 \mathrm{~m}$ away from the mixing section (73 pipe diameters) was used to image the dielectric components in the pipe flow phases by measuring rapidly and continually the capacitances of the passing flow across several crossing points in the mesh.

Experimental measurements were recorded with the aid of the above instrumentation across a range of liquid superficial velocities and air flow rates of between $0.05-0.47 \mathrm{~ms}^{-1}$ and $0.05-$ $4.73 \mathrm{~ms}^{-1}$, respectively. The flow patterns observed across these liquid and gas flow rates include: bubble, plug, slug flow and stratified wavy flows. The measurement sequence was programmed to allow simultaneous measurements and recordings from the WMS and ECT transducers [15]. The sampling frequencies of the ECT and WMS measurement transducers were 200 and 1,000 Hz, respectively. Figure 6 shows a plot of average void fractions recorded by the ECT and WMS measurement transducers. The data presented on the figure illustrates good agreement between the two methods of measurements. Some of the minor differences according to Abdulkadir et al. [15] may be due to the fact that the ECT takes measurements over larger axial distances than the WMS. 

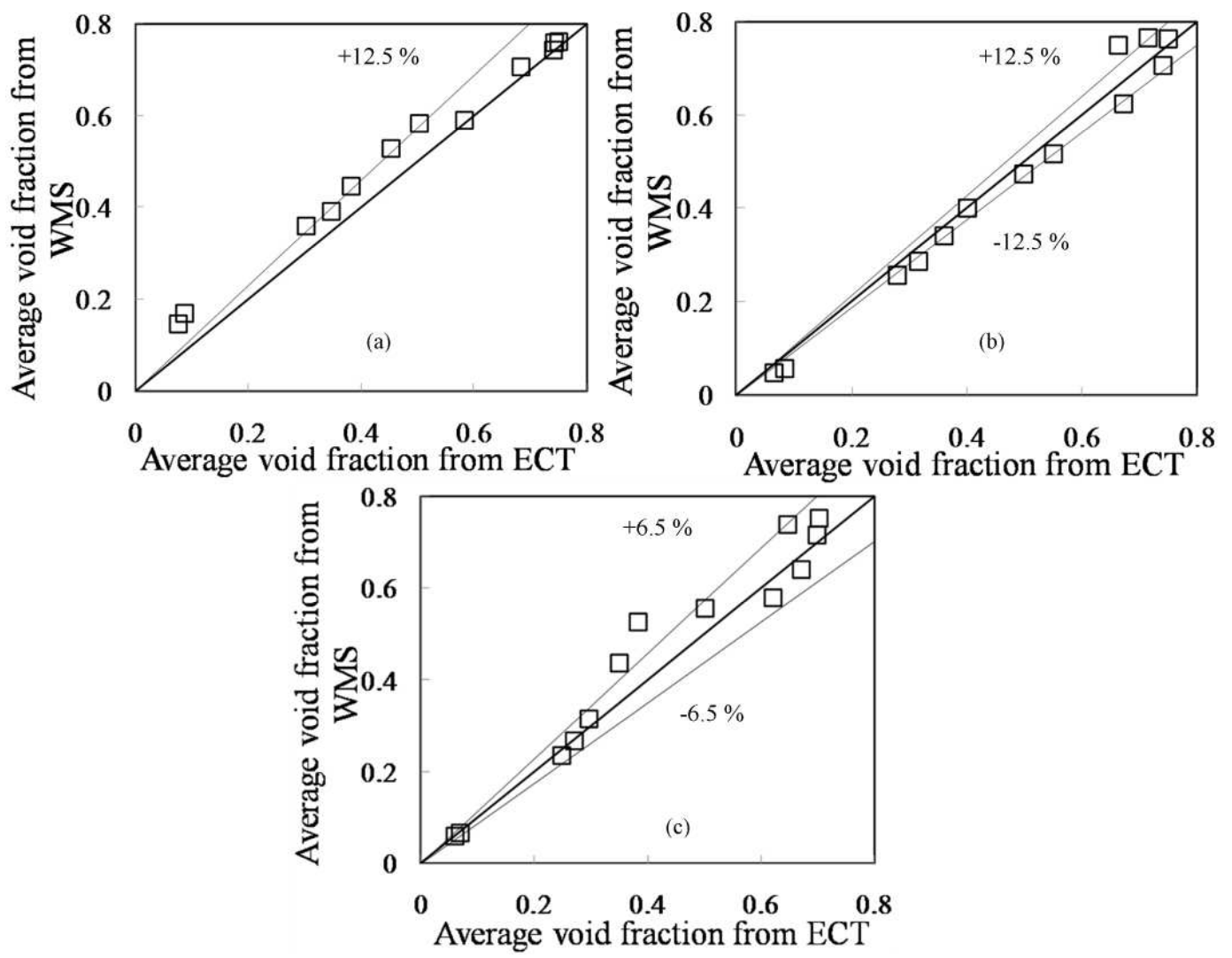

Figure 6: Comparison of average void fraction obtained from the ECT and WMS (a) Liquid superficial velocity $=0.14 \mathrm{~ms}^{-1}$ and gas superficial velocity $=0.05-4.73 \mathrm{~ms}^{-1}$ (b) Liquid superficial velocity $=0.28 \mathrm{~ms}^{-1}$ and gas superficial velocity $=0.05-4.73 \mathrm{~ms}^{-1}$ (c) Liquid superficial velocity $=0.38 \mathrm{~ms}^{-1}$ and gas superficial velocity $=$ $0.05-4.73 \mathrm{~ms}^{-1}$

\subsection{Flow development:}

To investigate the influence of pipeline length on slug flow, the void fractions determined from the measurements recorded by two ECT probes and a WMS transducer located as shown in Figure 7 along the horizontal test pipe section were examined to resolve the flow development. A fully developed flow is one where the observed flow pattern does not change with the distance downstream (Abdulkadir et al.[34]). To confirm such a flow development, a comparison of the observed average slug frequency and the determined PDFs of the measured void fractions are shown in Figure 8 and Table 5. 


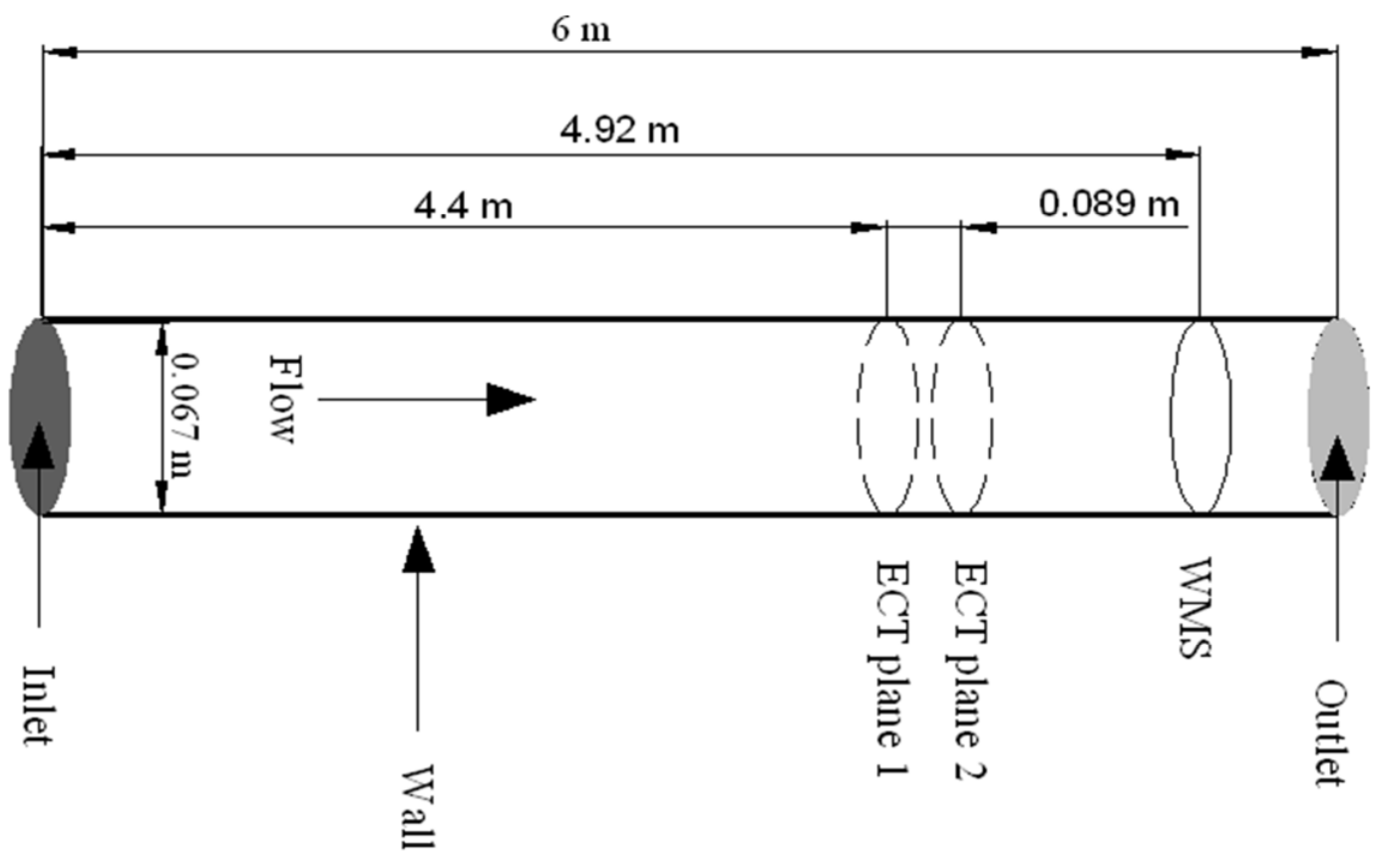

Figure 7: Horizontal pipeline used in this study showing measurement locations.

It is worth mentioning that a number of different gas-liquid mixers for two-phase flow have been described by other investigators. The choice of mixer geometry is often dictated by the flow pattern that is of primary interest. For an investigation that covers slug flow pattern, of which the present study is an example, Govier et al. [35] determined that the geometry of the mixing section affected the flow pattern only for a very short distance and that with an adequate calming section a simple tee was suitable. Some mixers according to [27] are also known to force stratified flow.

The average slug frequency and PDFs of void fraction of the recorded flow patterns are measured and determined across three cross-sections along the length of the horizontal pipeline length (at distances of 4,400 $\mathrm{mm}$ (64 pipe diameter), 4,489 $\mathrm{mm}$ (67 pipe diameter) and 4,920 $\mathrm{mm}$ (73.4 pipe diameter) downstream of the gas-liquid mixing section, which correspond to the location of the two ECT-planes and the single WMS measurement 
transducers, respectively as shown in Figure 7. The average slug frequencies and PDF of void fraction determined from the ECT and WMS measurements are used to identify any changes in characteristics of flow along the length of the pipeline.

An analysis of a plot of the measured average slug frequencies against axial distance is shown in Figure 8, where each of the three mesurement transducer locations did not identify any significant difference in the observed flow development. Consequently, it is concluded that the flow is fully developed at a distance of $4,400 \mathrm{~mm}$. This conclusion supports the previous findings of [34] who determined the variations in the void fractions recorded at distances of 64,65 , and 66.65 pipe diameters downstream of the mixer were small, and concluded that the flow is fully developed at 64 pipe diameters. This is aso in agreement with the findings of Weisman et al. [36] who claimed that with a simple mixing device, and in the absence of bends, an equilibrium situation is reached by $\mathrm{L} / \mathrm{D} \approx 60$. This conclusion was also reinforced by [37]. The small change in the flow development observed at an axial distance of $4,920 \mathrm{~mm}$, may be attributed to the slight disturbance that the more intrusive WMS transducer introduces to the flow.

An examination of the form of the determined PDF of void fraction shown on Table 4 conclude that the observed flow patterns are slug flows, characterized by a double peak trace, the lower peak representing the liquid slug and the higher peak reprsenting the, Taylor bubble. 


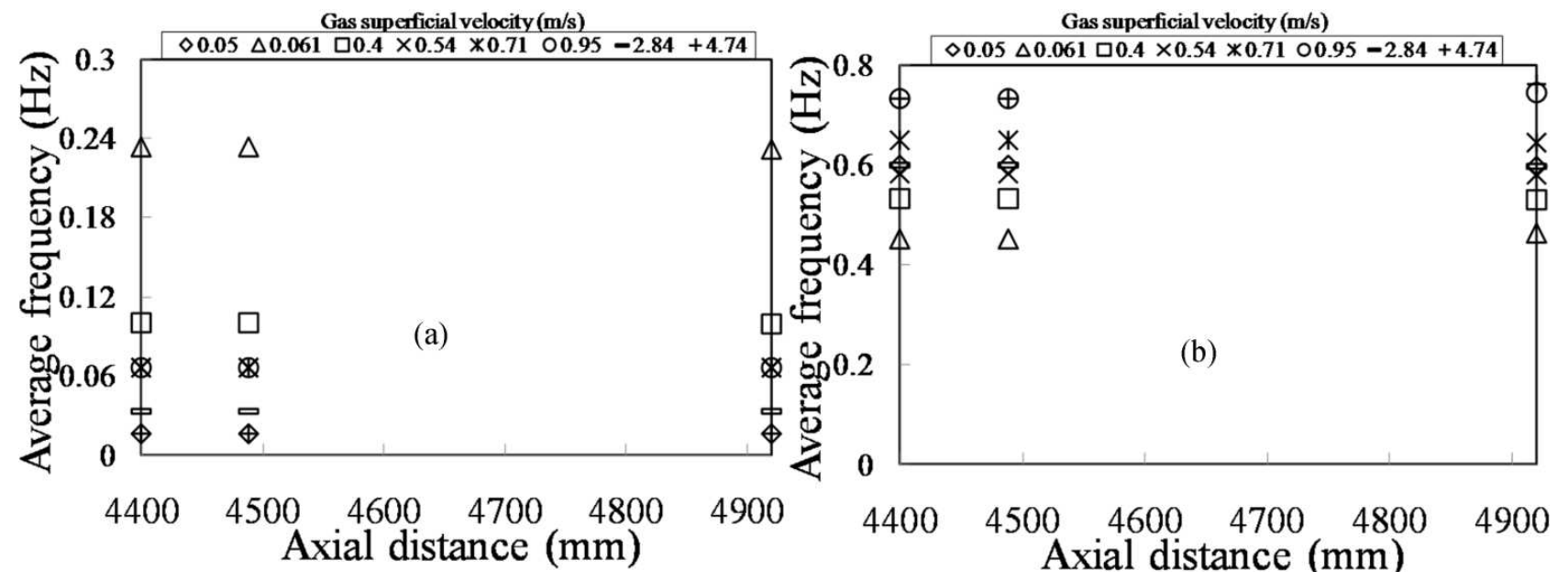

Figure 8: A plot of the average measured slug frequencies against the axial distance downstream of the gasliquid mixing section for the liquid superficial velocities $\left(\mathrm{ms}^{-1}\right)$ of: (a) 0.05 and (b) 0.38 .

Table 4: A plot of the PDF of void fraction measured at the three transducer locations along the length of the horizontal pipe downstream of the gas-liquid mixing section.

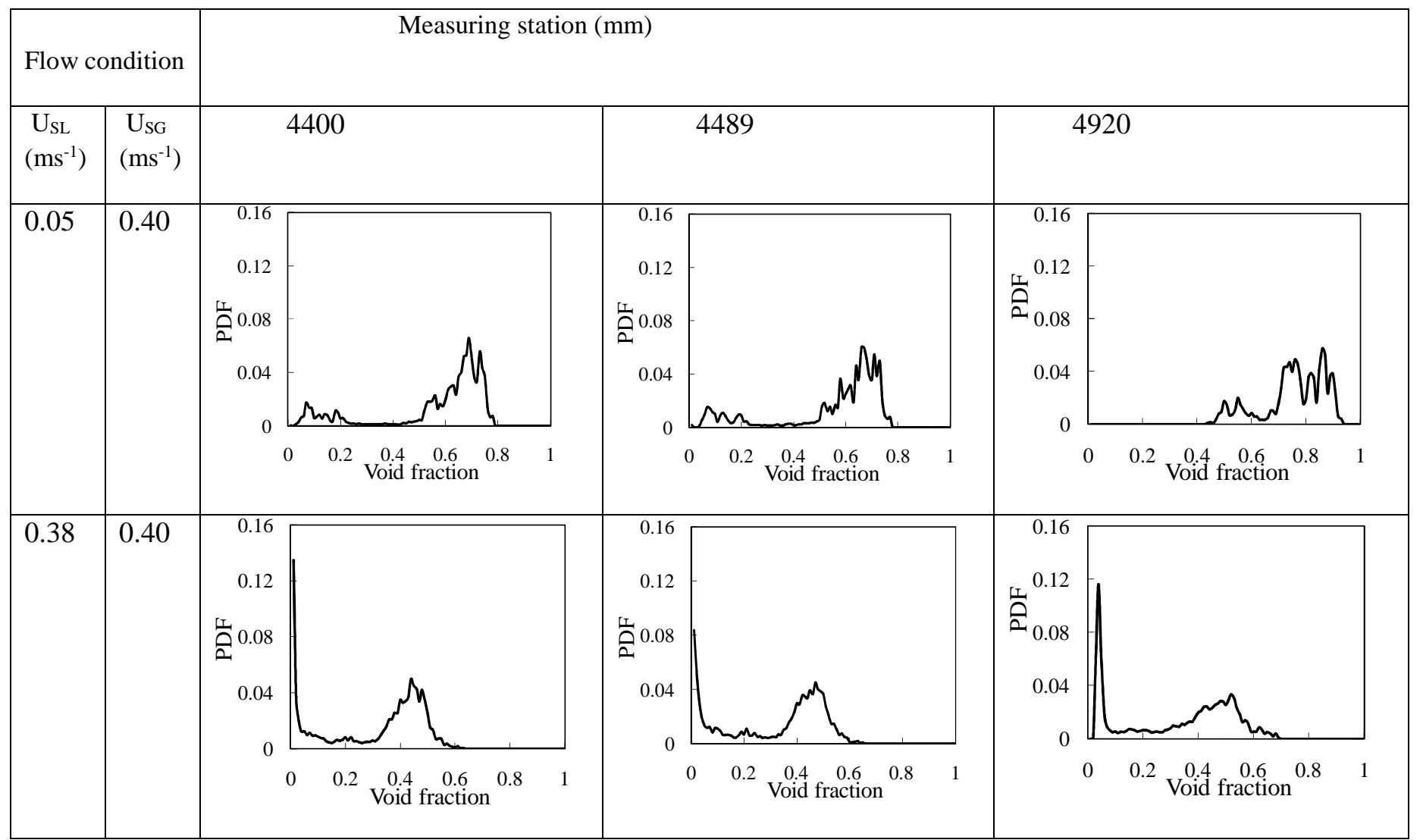




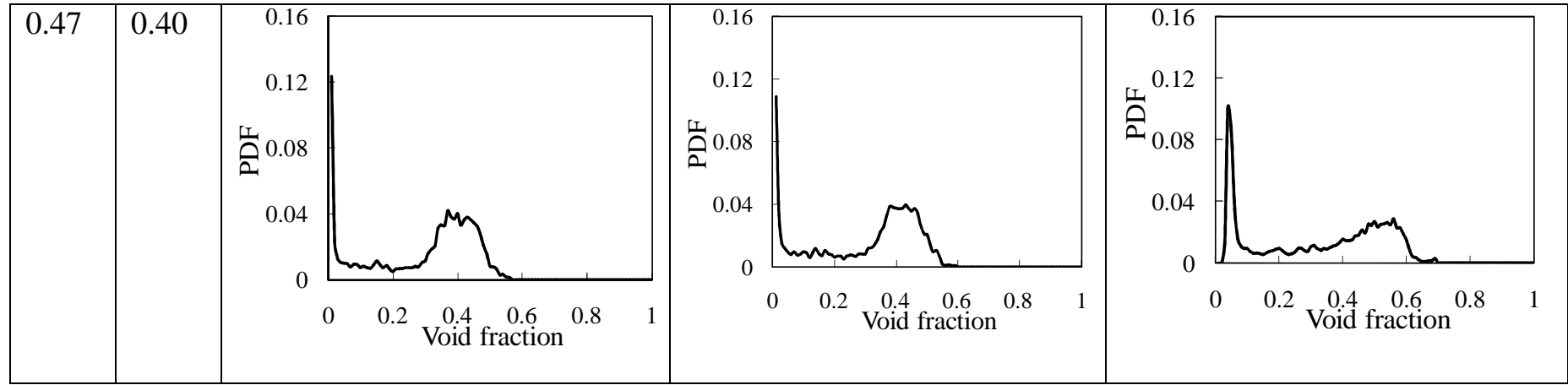

Another way to confirm flow development is to compare the slug front and tail velocities.

Comparison of slug front and slug tail:

The slug period $T_{u}$ is defined as the time that one slug unit takes to go through the position of the ECT. The inverse of the slug period $T_{u}$ is the slug frequency $f_{u}$ at a certain position from the inlet:

$$
f_{u}=\frac{1}{T_{u}}
$$

The average slug frequency is calculated as

$$
\overline{f_{u}}=\frac{\sum_{n=1}^{N} f_{u, n}}{N}
$$

The average of other parameters is calculated in an analogous way. The slug front and tail velocities, $U_{f}$ and $U_{t}$, respectively, are calculated by the identification of the arrival times of the slug front and tail at two adjacent planes, and then dividing the distance $\Delta x$ between them by the respective time differences $\Delta t$. The slug front and tail velocity between planes 1 and 2 example is then given by:

$\overline{U_{p}, S 1-S 2}=\frac{x_{S 2}-x_{S 1}}{t_{p, S 2}-t_{p, S 1}} ; p=[t, b]$

Where $p$ is the generic index representing either the slug front $t$ or the slug tail $b$. 
Comparison of slug front and slug tail can be a better indicator of flow development, as growing slugs might have different front and tail velocities. A computer program was developed to calculate slug front and tail velocities using equation (20). The program algorithm searches for the time delay between the two planes signals of the ECT when the liquid holdup is in the range [60-80] \%. This is done by finding the intersections between the liquid holdup signal and a horizontal line. Further steps are taken to make the program more robust when dealing with irregular cases, and finally the average is obtained. From the results summarized in Figure 9, we can see that the difference between slug front and tail velocities is small for most of the flow conditions. None of them is predominantly bigger than the other. This indicates good flow development. This is agreement with Ujang et al. [50], who reported frequency at different lengths, where flow development seems to be affected by the liquid superficial velocity; interpretation of their results suggest that a liquid superficial velocity of around $0.8-1.0 \mathrm{~m} / \mathrm{s}$ would be required for the development length to be more than $5 \mathrm{~m}$ in our pipe.

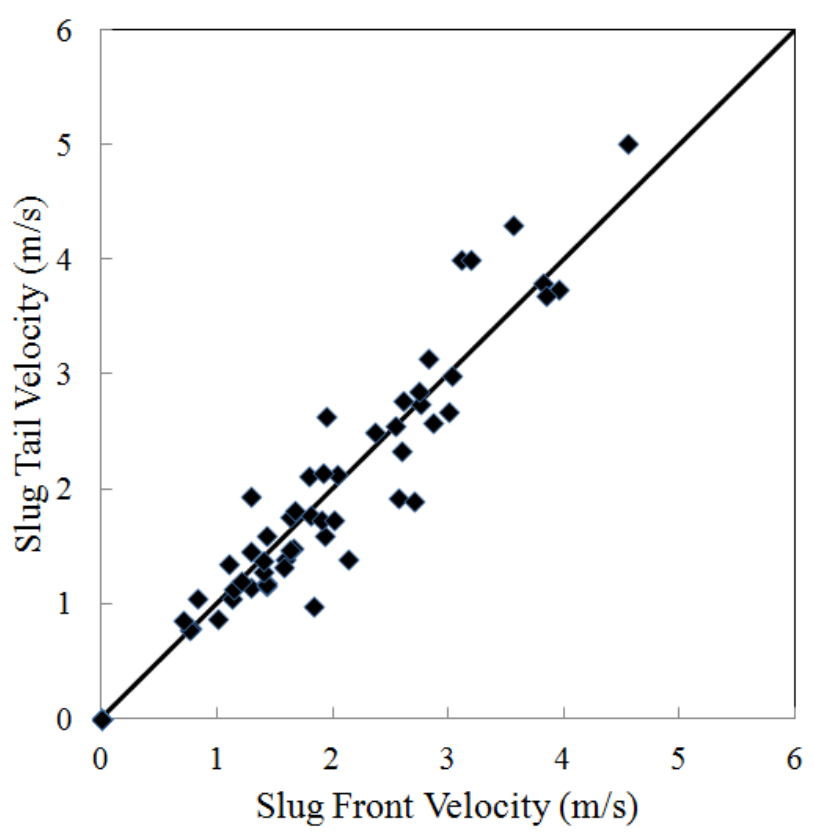

Figure 9: Comparison between slug front and tail velocities at different gas and liquid superficial velocities. 


\subsection{Determination of characterization parameters:}

(a) Translational Taylor bubble velocity:

Cross-correlation of the void fraction time series determined by the two ECT probes allows the translational velocity of periodical structures such as slugs to be determined. A plot of the time series of the void fractions recorded by the two ECT probes is shown in Figure 10. The details of the cross-correlation method can be found in [15]. The translational Taylor bubble velocities calculated for all of the experiments performed are presented in Figure 11.

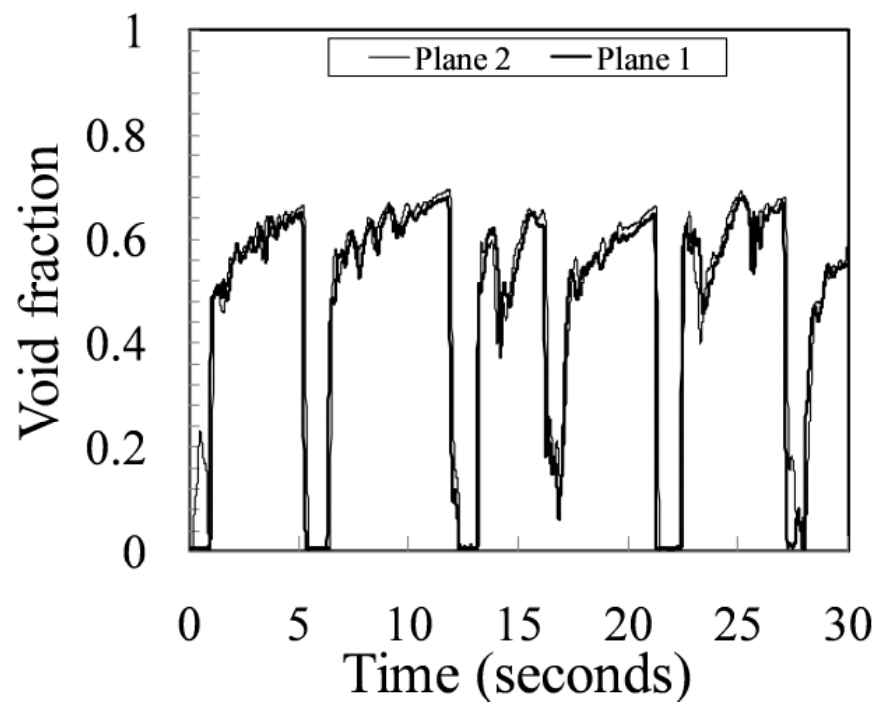

Figure 10: A typical plot of the void fraction signals from the two ECT probes. The distance between the two ECT probes is $89 \mathrm{~mm}$. Liquid and gas superficial velocities are $0.05 \mathrm{~ms}^{-1}$ and $0.34 \mathrm{~ms}^{-1}$, respectively.
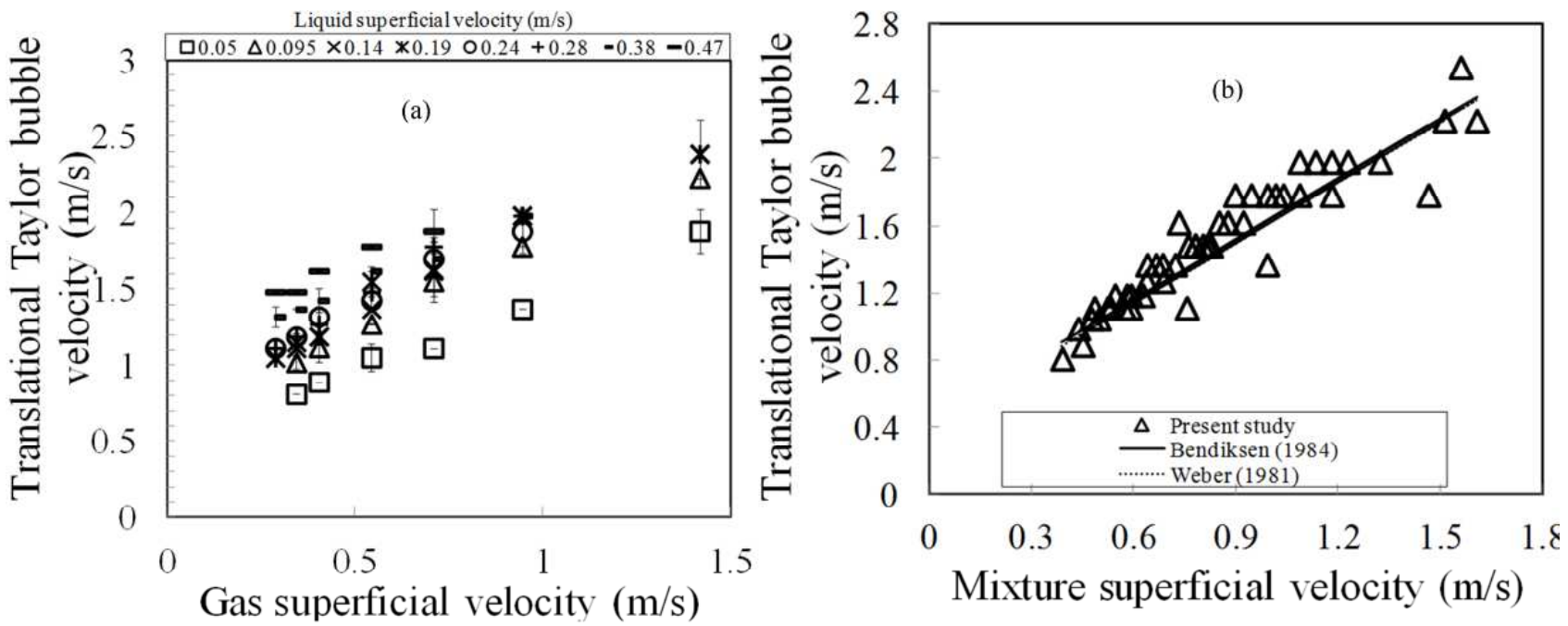

Figure 11: (a) Experimentally measured translational Taylor bubble velocity (structure velocity) as a function of mixture superficial velocity for the data corresponding to slug flow pattern. (b) Translational Taylor bubble 
velocity measured from experiment and empirical correlations. The empirical equations proposed by Weber [7] and Bendiksen [8] were recalculated using the physical properties of air and silicone oil.

Figure 11a shows the translational velocity of the Taylor bubble values calculated by crosscorrelating the signals from two ECT probes located $89 \mathrm{~mm}$ apart. It can be observed that for a given liquid superficial velocity, the translational velocity of the Taylor bubble increases with gas superficial velocity.

If the translational velocity of the Taylor bubble is linearized against mixture superficial velocity as shown in Figure $11 \mathrm{~b}$, the slope $C_{o}$ and the intercept $U_{o}$ are found to be 1.16 and 0.525 , respectively. Thus, the correlating line of the graph has the relationship

$U_{T}=1.16 U_{M}+0.525=1.16 U_{M}+0.648 \sqrt{g D}$.

Interestingly, it has been reported in the literature that $C_{o}$ varies between 1.2 and 1.35. Kouba [16]) experimentally concluded that $C_{o}$ can be as high as 1.8 for some flow conditions, low liquid and gas superficial velocities. More recently, [38] also reported an experimentally observed value of 1.20 for $C_{o}$ for a wide range of slug flow conditions. [15] reported $C_{o}=$ 1.39 for a vertical pipe using air-silicone oil mixture as the operating fluid. A $C_{o}$ value of 1.2 is usually assumed, which would represent the maximum velocity for fully developed turbulent flow.

The observed non-zero intercept of the line with the y-axis shows that there is a drift velocity component of bubbles. This observation supports the conclusions of [4] and [7-8] that a drift velocity exists for the horizontal case and that it may even exceed its value in the vertical case. 
A comparison of these experimentally measured translational Taylor bubble velocities, with the correlation functions derived by [7-8] is shown in Figure 10b. Interestingly, the data presented on the figure shows good agreement.

The ratio of the translational Taylor bubble velocity to mixture superficial velocity, $U_{T} / U_{M}$ is plotted against gas superficial velocity as shown in Figure 12. Many workers including Dukler and Hubbard [39] have reported values of this ration of between 1.25 and 1.3 for slug flow in small diameter pipes. Crowley et al. [40] report values of $U_{T} / U_{M}=2.0$ to 1.35 , for slug flow in a $17 \mathrm{~cm}$ internal diameter pipe, dependant on the fluid properties. [25] reported that the ratio of $U_{T} / U_{M}$ decreases continuously from 2.0 at low gas superficial velocities to 1.25 at high gas velocity and further that increasing liquid superficial velocity will increase the value of $U_{T} / U_{M}$ at lower gas velocities.

Figure 12 shows that at liquid and gas superficial velocities of 0.05 and $0.34 \mathrm{~ms}^{-1}$, respectively, $U_{T} / U_{M}=2.1$. However, as the gas superficial velocity is gradually increased, $U_{T} / U_{M}$ decreases continuously from 2.1 to 1.3 . These observations are consistent with the conclusions of [25]. It can be concluded that for the eight liquid superficial velocities considered here that the value of $U_{T} / U_{M}$ is between 1.3 and 2.3 and decreases systematically with increasing gas superficial velocity. 


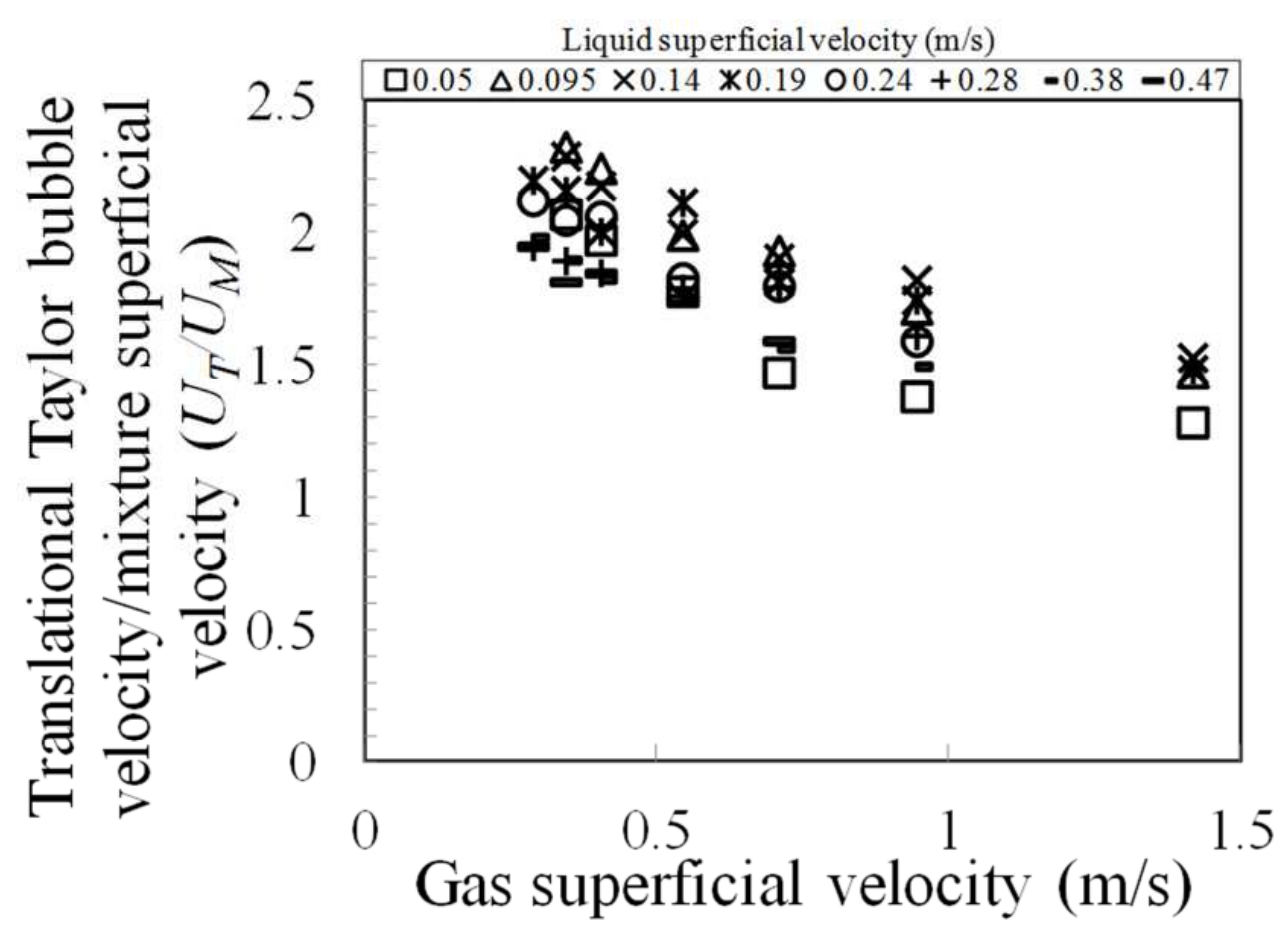

Figure 12: Variation of the ratio of translational Taylor bubble velocity, $U_{T} / U_{M}$ with gas superficial velocity across a range of liquid superficial velocities

(b) Pressure gradient:

The pressure gradient developed across the test pipe section was measured using a differential pressure (DP) transducer cell connected to measurement tapings located around the circumference of pipe section located equidistant upstream and downstream of the twinplane ECT probes. The distance between the DP cell tappings was $0.86 \mathrm{~m}$.

Figure 13 presents a plot of the frictional pressure gradient measured as the gas superficial velocity is increased, for a range of increasing liquid superficial velocities. The plot shows that in general the frictional pressure gradient increases with gas superficial velocity except at liquid superficial velocity of $0.05 \mathrm{~ms}^{-1}$ wherein it decreases with an increase in gas superficial velocity. In general, the observed increase in frictional pressure gradient can be attributed to an increase in shear stress between the liquid and the walls of the pipe and comparatively larger bubbles are observed to form due to coalescence, which causes a decrease in the liquid velocity due to higher level of liquid holdup, hence increases the frictional pressure drop. 
These observations support the phenomena reported by Beggs and Brill [41] and [42]. The decrease on the other hand could be attributed to the fact that the slugs are completely frothy and as a consequence results in a decrease in frictional pressure gradient with an increase in gas superficial velocity. A similar observation was reported by [25].

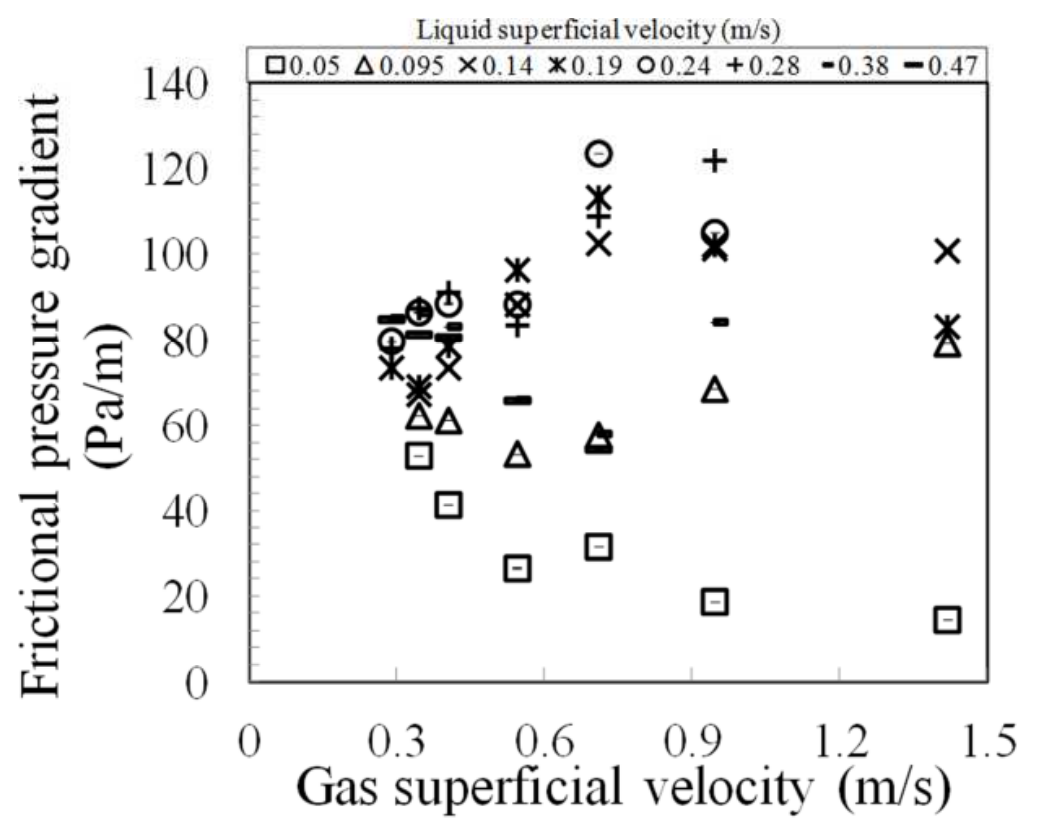

Figure 13: A plot of the frictional pressure gradient measured as the gas superficial velocity is increased for a range of increasing liquid superficial velocities.

(c) Average cross-sectional void fraction:

Figure 14 shows that the average void fraction spans in the range of $0.23 \leq \bar{\varepsilon} \leq 0.78$. It is evident that, in general, the average void fraction increases with an increase in gas superficial velocity at constant liquid superficial velocity. However, at liquid superficial velocity of 0.05 $\mathrm{ms}^{-1}$, small fluctuations happen, which could be attributed to bubble collapse and air entrainment in the liquid layer as a result of an increase in the gas flow rate. 


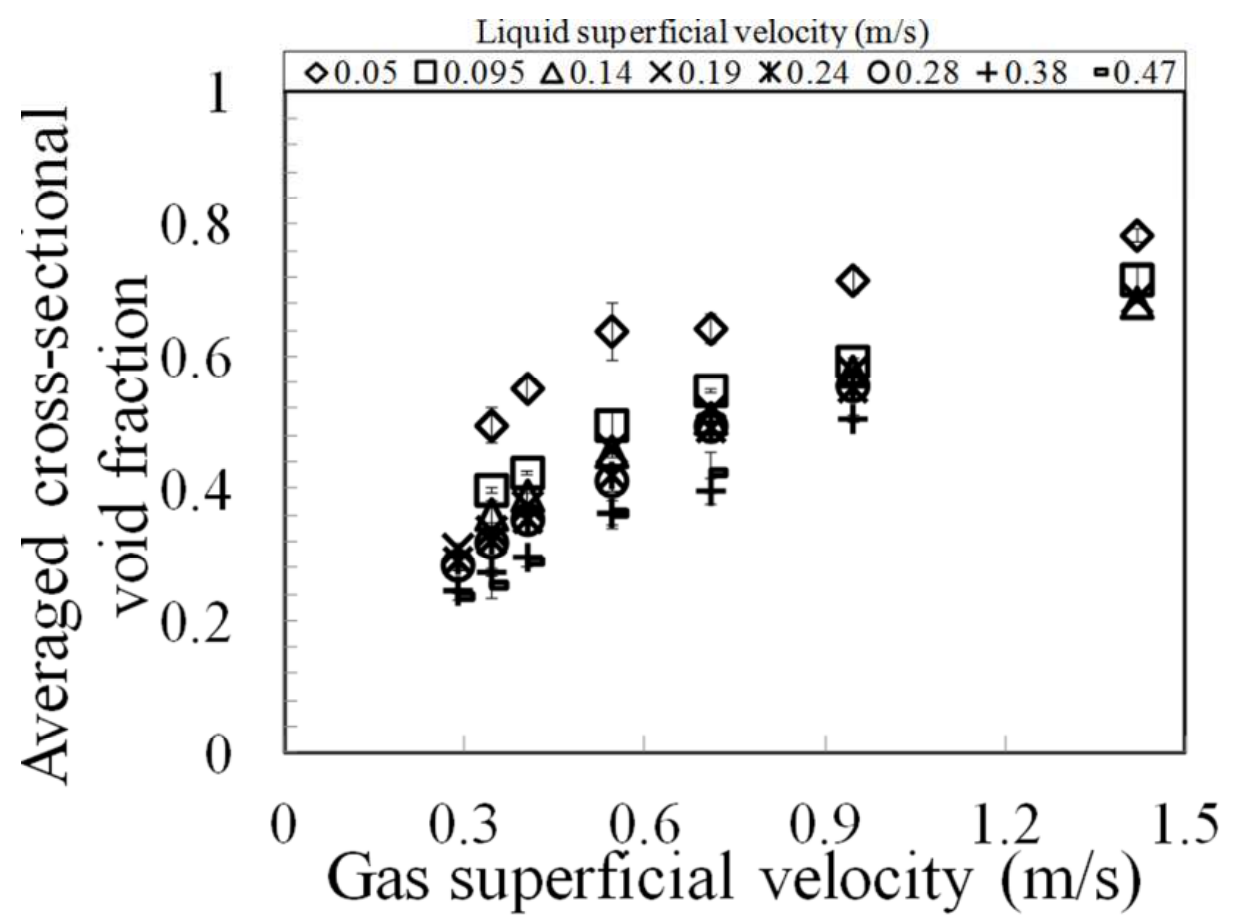

Figure 14: The effect of gas superficial velocity on the average cross-sectional void fraction. The bars represent the standard deviation for all measurements made

(d) Void fraction in the liquid slug and Taylor bubble:

The determination of the slug holdup is considered one of the primary parameters to the solution of slug flow models. This is because the solution of the averaged momentum and balance equations requires an independent method to predict the liquid holdup averaged over the volume of the slug. Consequently, the characteristic lengths, pressure drops and velocities to be computed are functions of the averaged voids.

In the present work, regular slugs are identified from the PDF of void fraction forms suggested by [23]. PDF functions are bimodal for slug flow illustrated in Figure 4. Here, the PDF of void fraction shows two main peaks, low and high void fraction corresponding to 0.06 and 0.72 , respectively. These peaks are the signatures of the aerated liquid slug and the Taylor bubble. 
The void fraction data shown in Figure 15 are the average void fraction in the liquid slugs. These values are of regular slugs. It can be observed that for these conditions void fraction is almost insensitive to both the liquid and gas superficial velocities. This is in agreement with the findings of [23], [39] and [42].

Figure 16 compares the present data against values predicted by correlations proposed by Gregory and Scott [5], [13] and [18]. It is seen that there is better agreement between present experimental data and the correlation of [5] as shown in the figure. The error of agreement is $\pm 30 \%$.

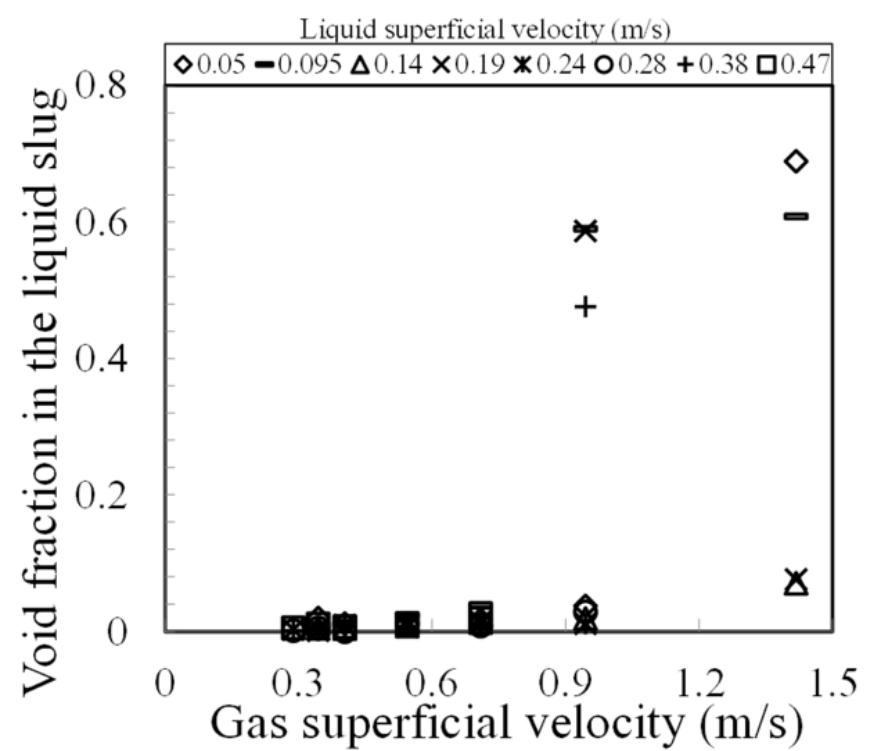

Figure 15: The determined mean gas void fractions in the liquid slug 


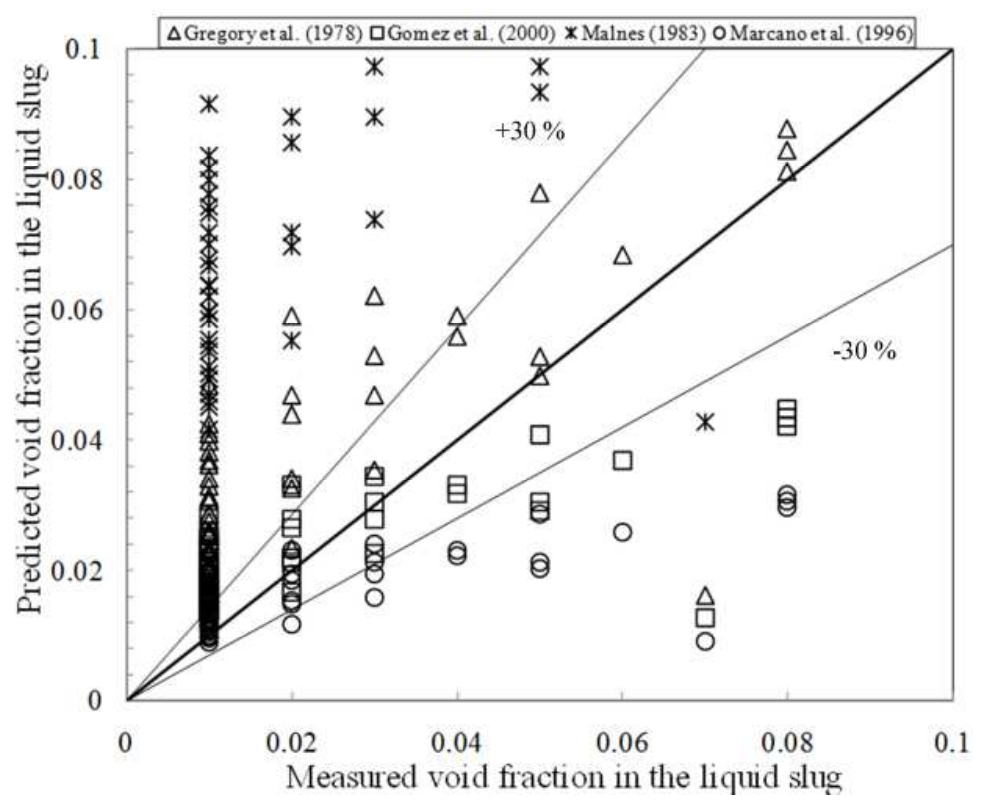

Figure 16: Comparison between the experimental data and the considered empirical correlations

Figure 17 presents a plot of the void fraction in the Taylor bubble against the gas superficial velocity. It is observed that the void fraction in the Taylor bubble increases as the gas velocity increases. At liquid superficial velocities of between $0.14-0.47 \mathrm{~ms}^{-1}$, an exponential relationship is established between the void fraction in the Taylor bubble and the gas superficial velocity. Contrary to this, at a liquid superficial velocity of $0.05 \mathrm{~ms}^{-1}$, the void fraction in the Taylor bubble increases exponentially from 0.67 to 0.70 at gas superficial velocity of 0.34 to $0.54 \mathrm{~ms}^{-1}$, respectively. It then decreases a little and then increased from 0.69 to 0.73 . The observed increase according to [15] may be as a result of an increase in bubble population observed in the liquid slug which may then coalesce with the Taylor bubble. At liquid superficial velocity of $0.24 \mathrm{~ms}^{-1}$, the relationship between void fraction in the Taylor bubble and gas superficial velocity is almost linear. 


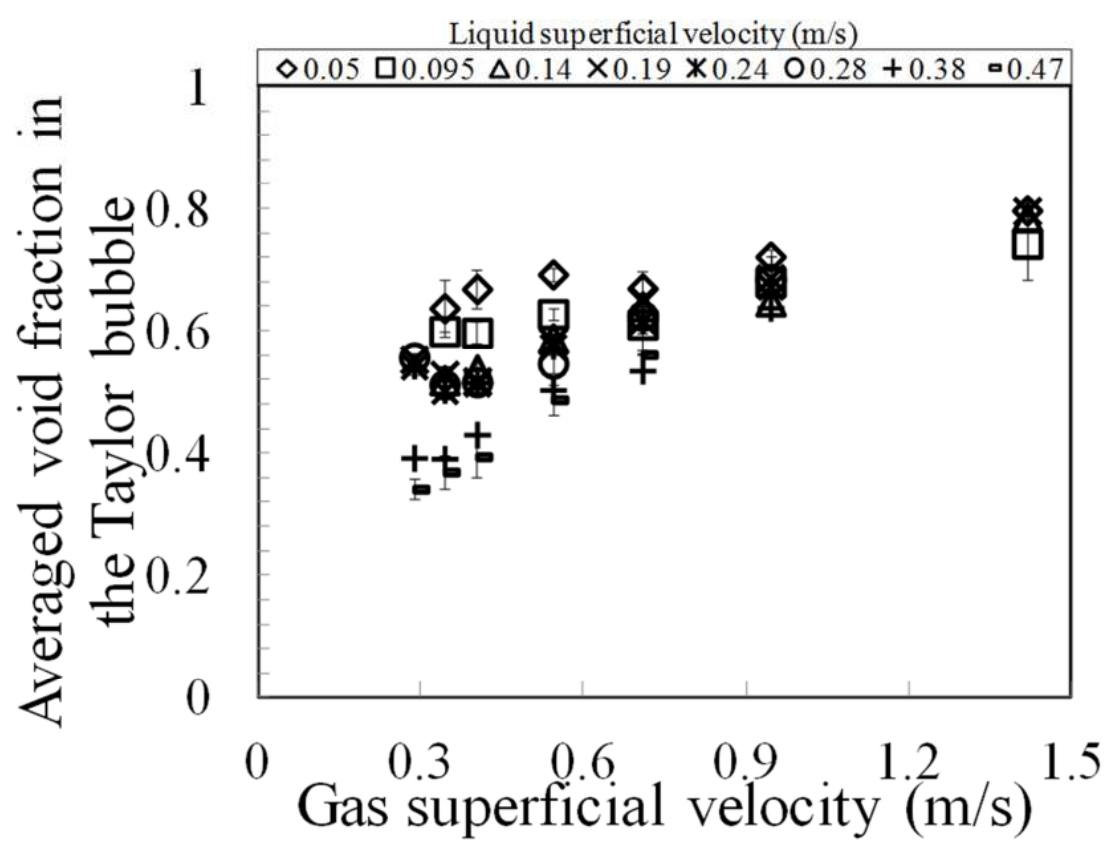

Figure 17: The determined mean gas void fractions in the Taylor bubbles. Liquid superficial velocity $\left(\mathrm{ms}^{-1}\right)$ : $0.05-0.47$. The bars represent the standard deviation for all measurements made

Figure 18 presents a dependence of void fraction in the Taylor bubble $\left(\varepsilon_{T B}\right)$ on the void fraction in the slug body $\left(\varepsilon_{S}\right)$. Two regions are identified: (a) $\varepsilon_{S}<0.1$ and (b) $0.25<\varepsilon_{S}<$ 0.4. For both regions, interestingly, $\varepsilon_{T B}$ can be observed to have a maximum value of 0.8 with an increase in $\varepsilon_{S}$. In the region $\varepsilon_{S}<0.1$, the liquid slug can be classified as a homogeneous bubble flow whilst on the other hand, the liquid slug can be seen as a developing Taylor bubble in the region $0.25<\varepsilon_{S}<0.4$. 


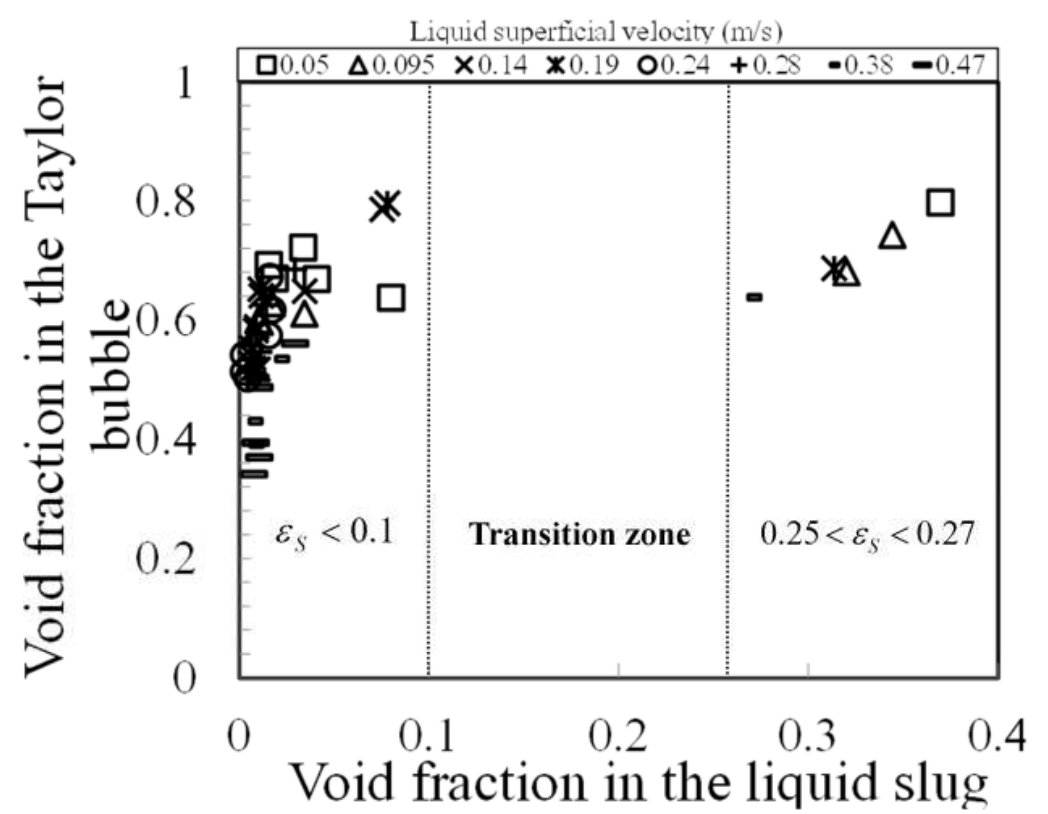

Figure 18: Dependency of void fraction in the Taylor bubble on the void fraction in the liquid slug at different liquid superficial velocities.

(e) Slug length:

Another primary variable in slug flow modelling is the slug length, $L_{S}$. It is important for fluids deliverability, flow assurance, and pipeline and surface facility designs. It is worth mentioning that slug frequency and its length are two quantities that are strongly interrelated. First in Figure 19, the behaviour of the ratio $L_{S} / L_{T B}$ as a function of gas superficial velocity at different liquid superficial velocities is presented. It is interesting to observe from the figure that as expected, $L_{S} / L_{T B}$ in general decreases with an increase in gas superficial velocity. Contrary to this, at liquid superficial velocity of $0.05 \mathrm{~ms}^{-1}, L_{S} / L_{T B}$ is almost independent of gas superficial velocity. $L_{S} / L_{T B}$ seems to approach zero as gas superficial velocity gets bigger. Interestingly, for region below the dash line as depicted in Figure 18, the length of the Taylor bubble is bigger than liquid slug while on the other hand, liquid slug is longer for the region above the dash line. 


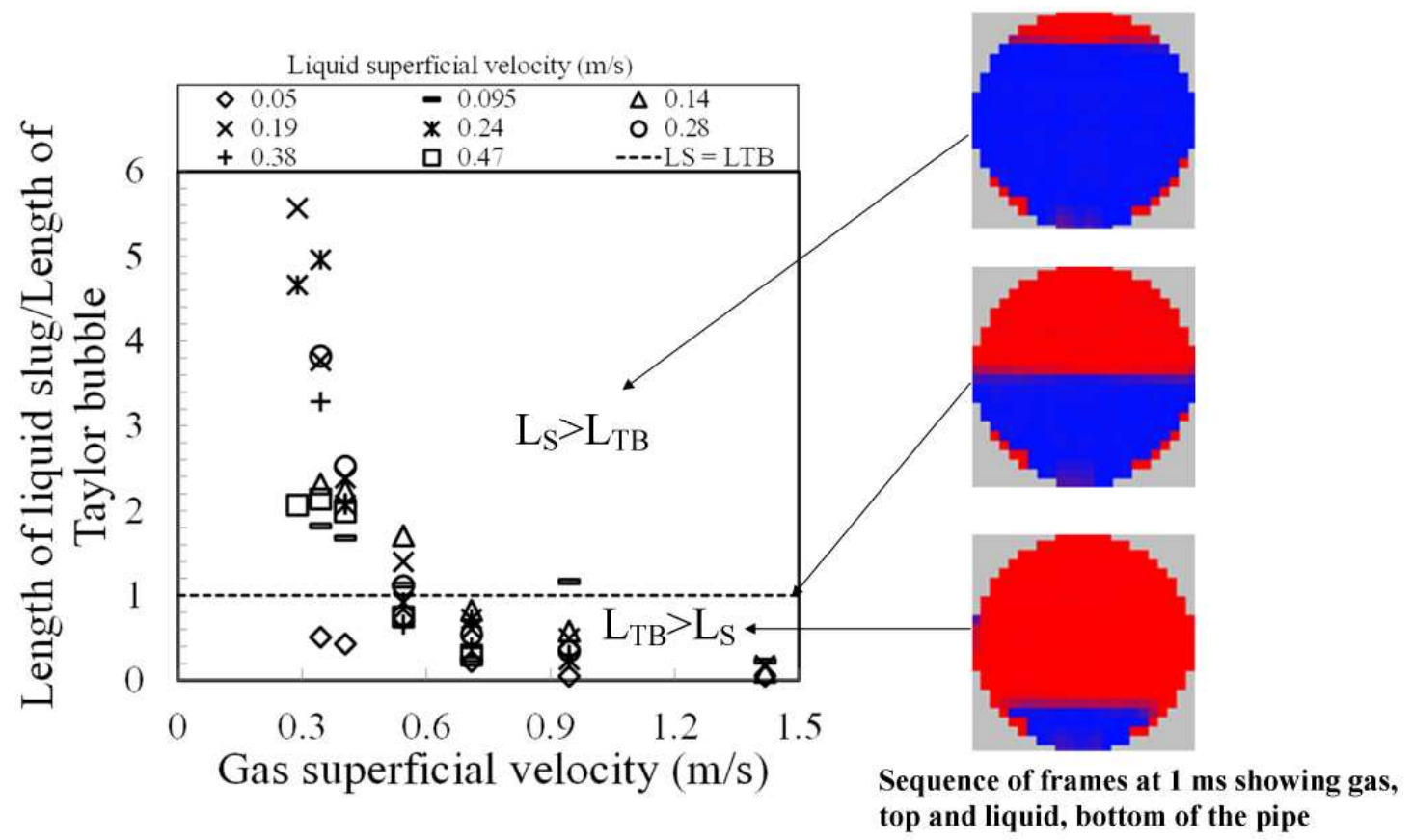

Figure 19: Average length of liquid slug/length of Taylor bubble as a function of gas superficial velocity at different liquid superficial velocities

The slug unit length, which is defined as the sum of slug and Taylor bubble (film) lengths

$L_{U}=L_{S}+L_{T B}$

is determined by multiplying the translational Taylor bubble velocity by the time taken for the slug unit to travel the distance between the two ECT probes. Thus, the length of a slug unit is given by

$$
L_{U}=\frac{U_{T}}{f_{s}}
$$

Figure 20 illustrates a plot of the measured average dimensionless slug unit length against the gas superficial velocity. These lengths were determined over an average experimental measurement period of 60 seconds. It can be observed that in general the length of the slug unit increases linearly as the gas superficial velocity increases. For convenience, a dimensionless scaled length is introduced, which is defined as the ratio of length of the observed slug unit divided by the test pipe diameter. It is observed that this length decreases 
as the liquid superficial velocity is increased from 0.05 to $0.47 \mathrm{~ms}^{-1}$ at gas superficial velocity of $0.54 \mathrm{~ms}^{-1}$. This is to be expected as the frequency of slugging increases as the gas superficial velocity is increased. A similar observation was reported by [19].

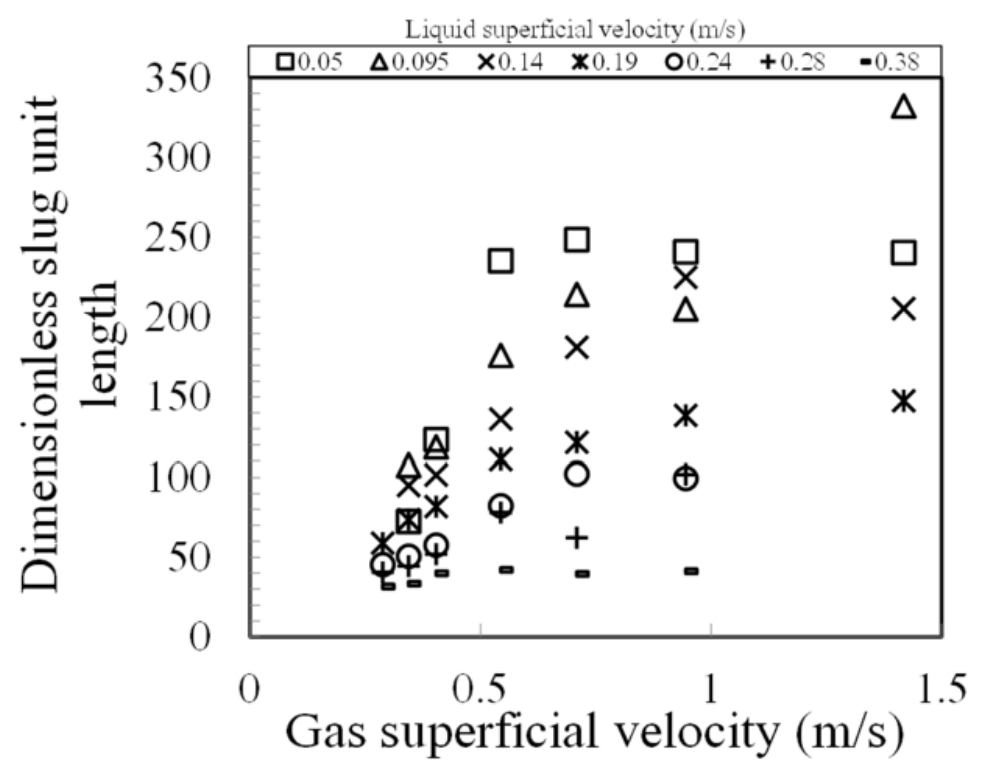

Figure 20: Illustrates a plot of the measured dimensionles average slug unit length against the gas superficial velocity. These lengths were determined over an average experimental measurement period of 60 seconds.

By combining the values obtained from equations (22) and (23), the slug and Taylor bubble lengths may be determined using the following two expressions:

$L_{T B}=\frac{L_{U}}{\frac{L_{T B}}{L_{S}}+1}$

$L_{S}=L_{U}-L_{T B}$

Figure 21 illustrates a plot of the average dimensionless liquid slug length against dimensionless unit slug unit length for a range of increasing liquid superficial velocities. An examination of these data trends confirm the characteristic irregularity and intermittency associated with slug flows. A similar trend was reported by [19]. Interestingly, the observed slug lengths are in the order of 8 to 46 pipe diameters, and appear relatively independent of 
the flow conditions. A number of other investigators [4], [39], and [43-44] have observed a fairly constant slug length of between 10 to 40 pipe diameters for similar set of flow conditions.

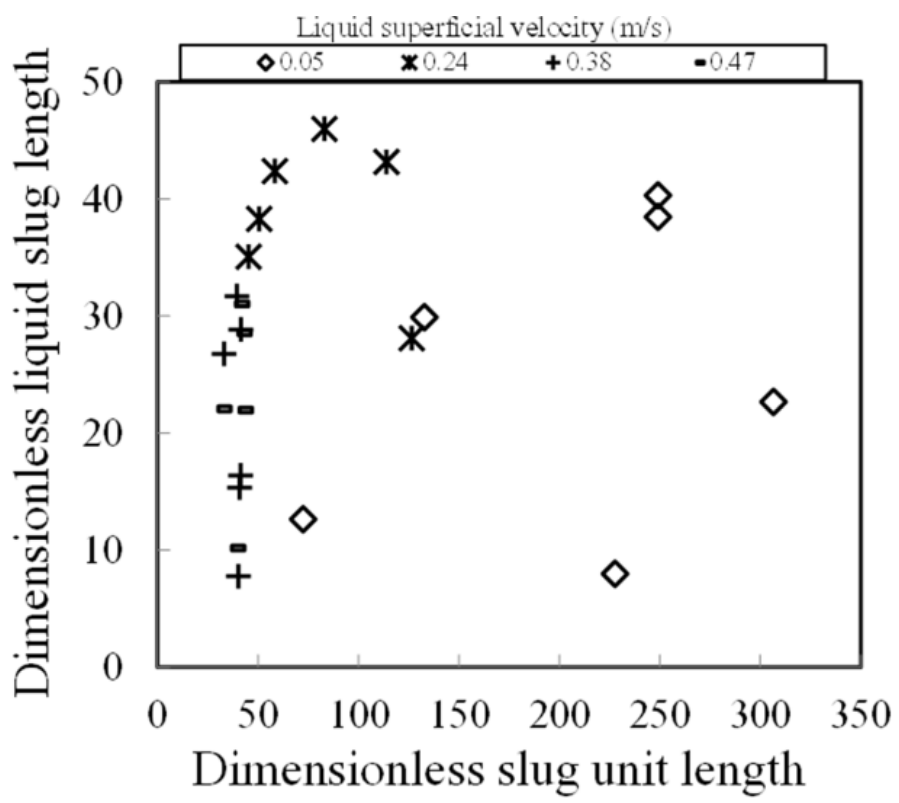

Figure 21: A plot of the average dimensionless liquid slug length of the dimensionless slug unit length for a range of increasing liquid superficial velocities

Figure 22 presents a plot of the average dimensionless Taylor bubble length against the dimensionless slug unit length for a range of increasing liquid superficial velocities.

It is clear that the Taylor bubble length follows a near linear relationship with the total slug unit length. Thus, it may be regarded that the length of the Taylor bubble constitutes the main length component of the slug unit. 


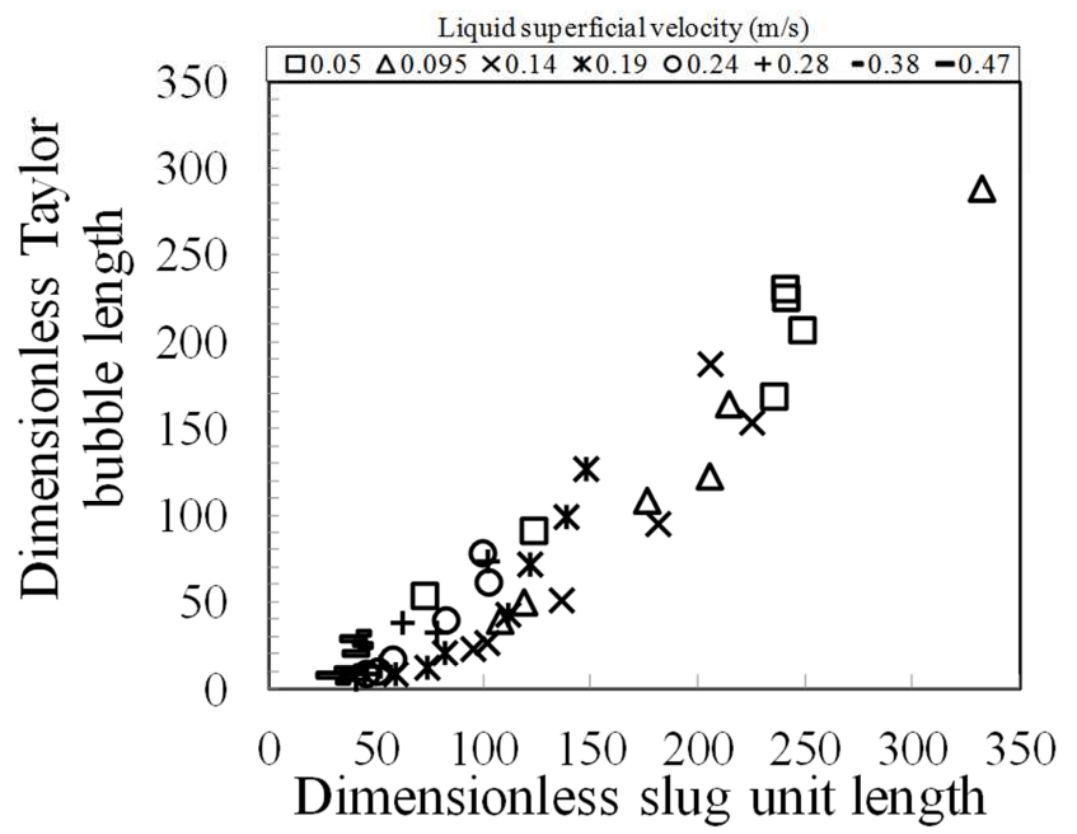

Figure 22: A plot of the average dimensionless Taylor bubble length against the dimensionless slug unit length for a range of increasing liquid superficial velocities

Figure 23 depicts a plot of the average liquid slug length as a function of slug frequency for a range of increasing liquid superficial velocities. It is observed that in general the slug length tends to decrease as the slug frequency increases.

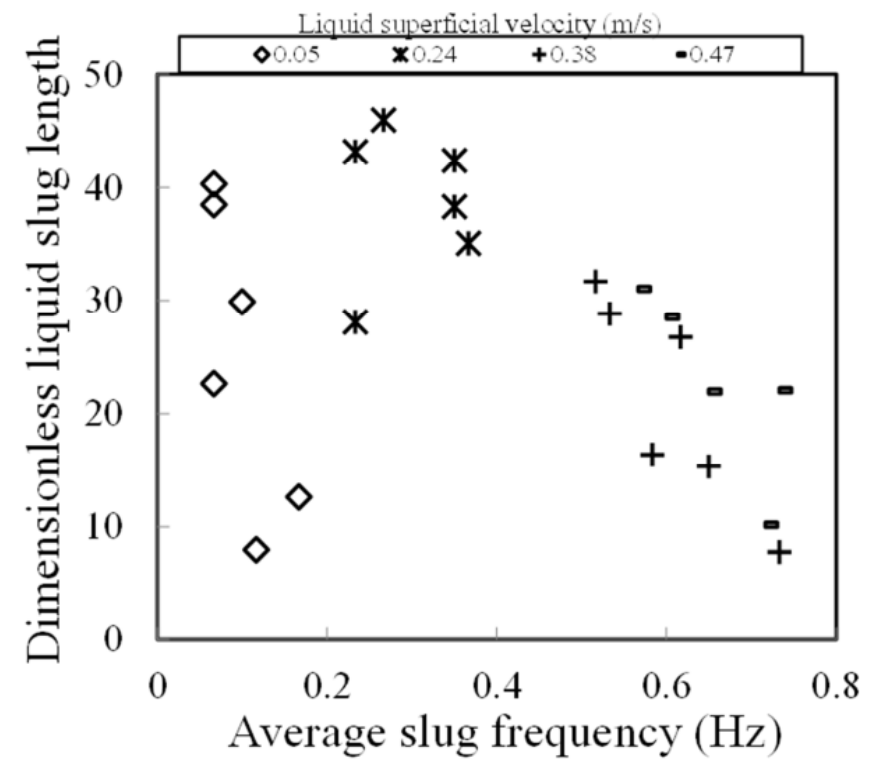

Figure 23: A plot of the average liquid slug length as a function of slug frequency for a range of increasing liquid superficial velocities 
(f) Frequency:

According to [5] and [14], slug frequency may be defined as the average number of slugs per unit time as seen by a stationary observer.

Intermittent flow is characterized by a variation of the observed void fraction with time, mainly in the form of periodic structures. To characterize these structures, an analysis of the fluctuations in void fraction time series was conducted to determine the frequency employing the Power Spectral Density (PSD) method, detailed in [15].

Figure 24 presents a plot of the average slug frequency against liquid superficial velocity for an increasing range of selected gas superficial velocities. It shows that the average slug frequency is fairly weakly dependent on the gas superficial velocity for all of the liquid superficial velocities examined. However, the average slug frequency is clearly observed to increase as the liquid superficial velocities increase, which confirms the findings of Manolis et al. [45]. This phenomenon may be explained in that the presence of more liquid may be expected to lead to the generation of more slugs as the gas superficial velocity increases.

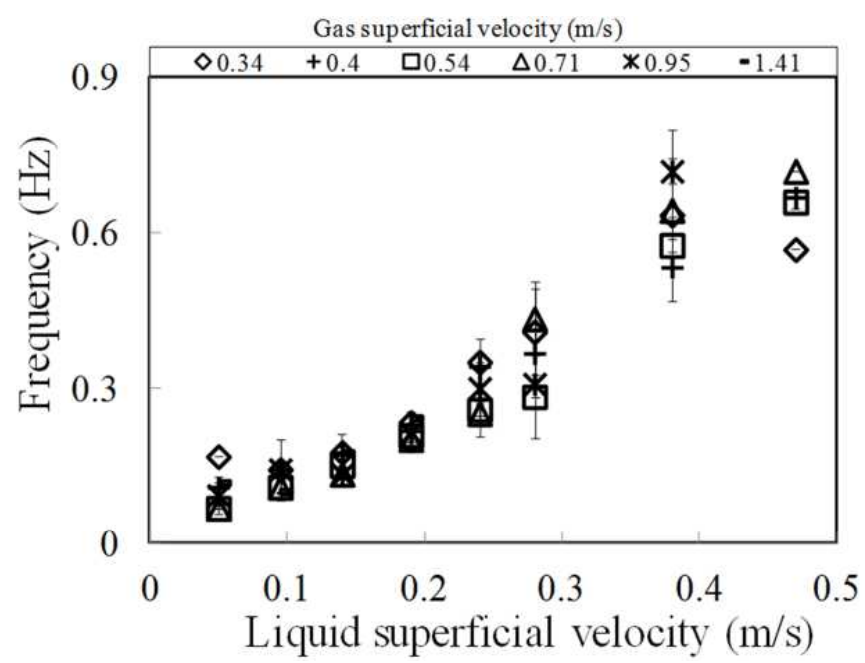

Figure 24: A plot of the average slug frequency against the liquid superficial velocity for a range of increasing gas superficial velocities. Liquid superficial velocity $\left(\mathrm{ms}^{-1}\right): 0.05-0.47$. The bars represent the standard deviation for all measurements made. 
Comparison of experimentally determined slug frequency against slug frequency obtained from empirical correlations:

Figures 25 and 26 compare the measured slug frequencies against the empirical equations proposed by [5] and [23], and [25-26].

From an examination of these figures it is observed that the predicted values of [23] exhibit the greatest discrepancy to the experimental data across all of the liquid superficial velocities considered. The closest agreement between experiment and predicted values is found employing the [26] correlation. The discrepancy with the work of [23] may be that this correlation method only considers liquid superficial velocity as a parameter and does not consider the effect of fluid properties and pipe diameter. Thus, the methods proposed by [5], [23], and [25] may deviate the measured experimental values by several orders of magnitude. Thus, in conclusion the [26] correlation method gave the closest agreement to the current experiment data. 

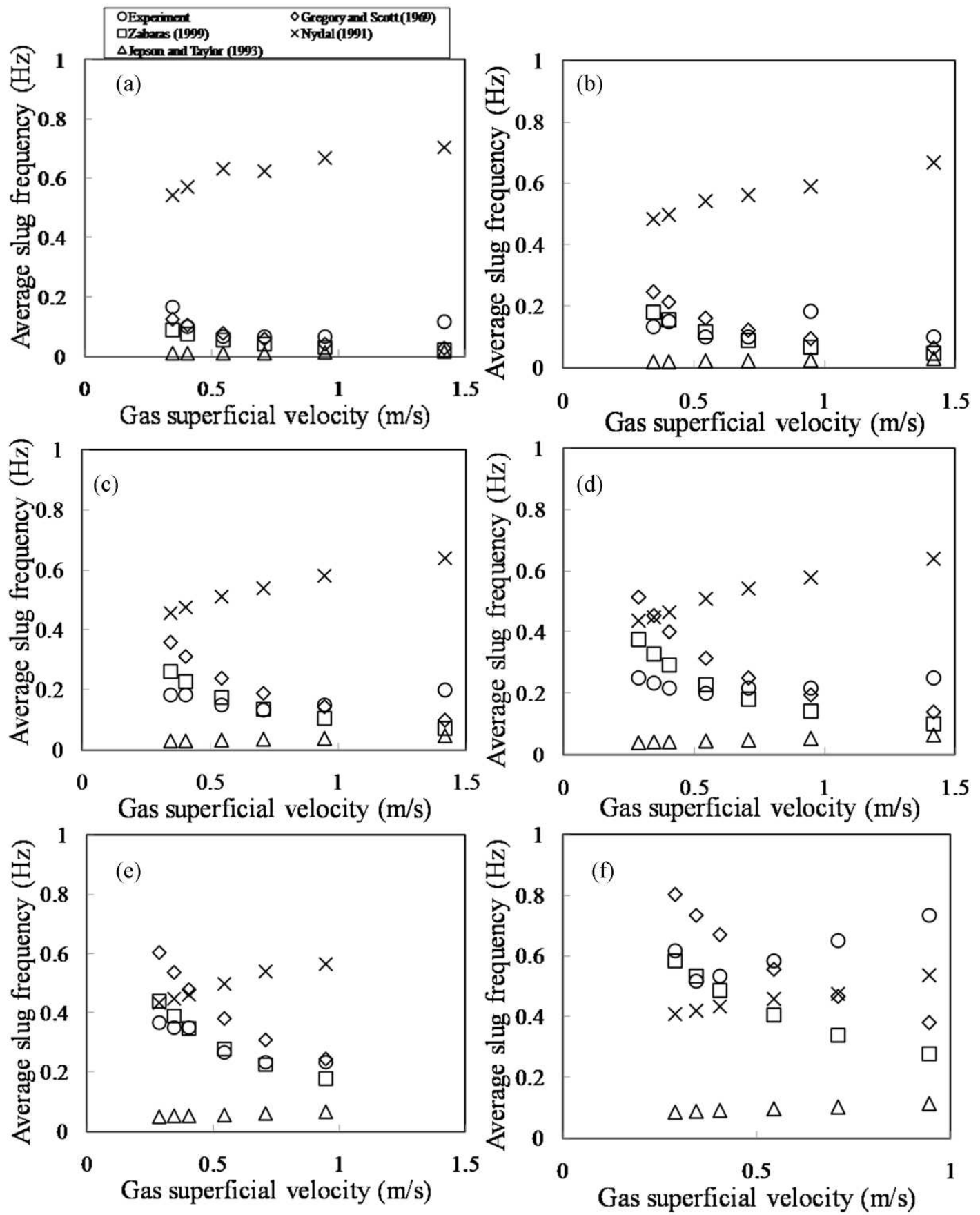

Figure 25: Plots of the variation of average slug frequency with gas superficial velocity using results obtained from experiments and empirical correlations for the following liquid superficial velocities ( $\mathrm{ms}^{-1}$ ): (a) 0.05 (b) 0.095 (c) 0.14 (d) 0.19 (e) 0.24 (f) 0.38 


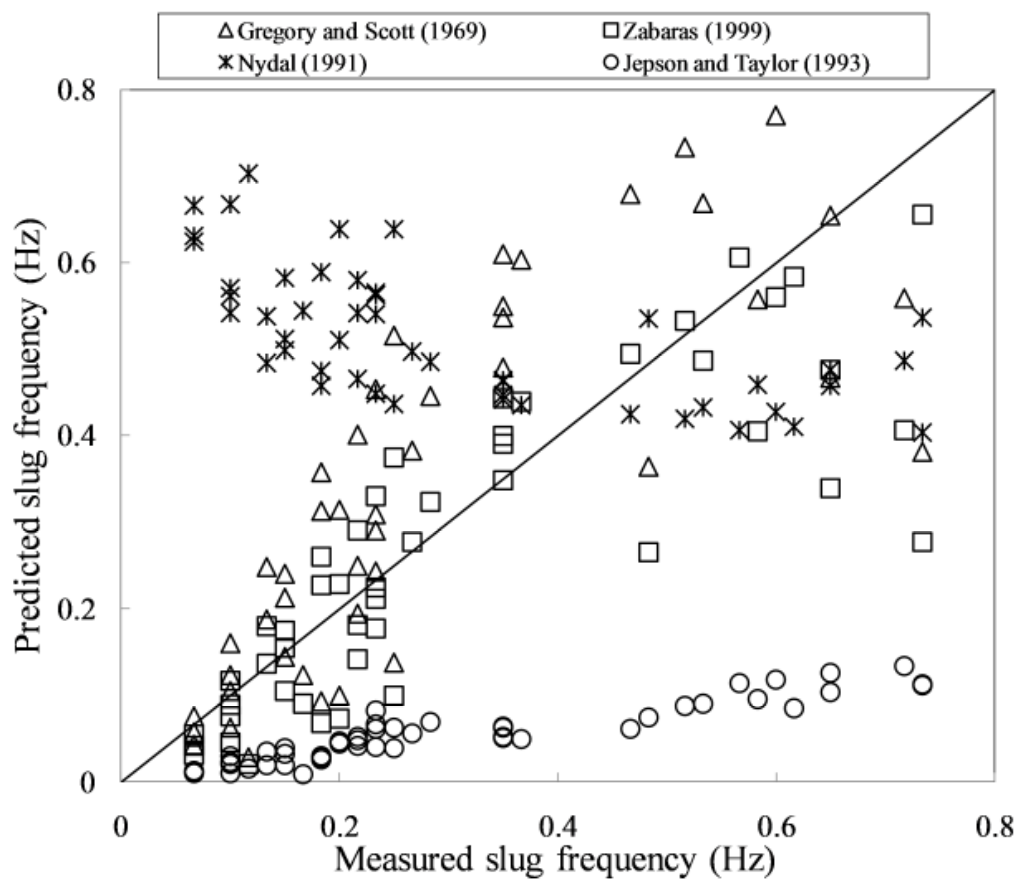

Figure 26: A plot to compare the experimental data against the results of previously published empirical correlation models

Figure 27 illustrates a plot of the dimensionless Strouhal number St, defined as $\frac{f D}{U_{S G}}$ as a function of the liquid volume fraction $x_{L}$ It can be observed from the plot that the experimentally computed $S t$ values correlate well with those predicted by the model proposed by Fossa et al. [46] whose constants were inferred from an analysis of the experimental measurements:

$S t=\frac{f D}{U_{S G}}=\frac{A x_{L}}{1+B x_{L}+C x_{L}^{2}}=\frac{0.044 x_{L}}{1-1.71 x_{L}+0.70 x_{L}^{2}}$

Although, the length of the test section used in the experiments conducted by [43] was only $12 \mathrm{~m}$ long, they exhibit close agreement with the data derived from the present experimental measurements. 


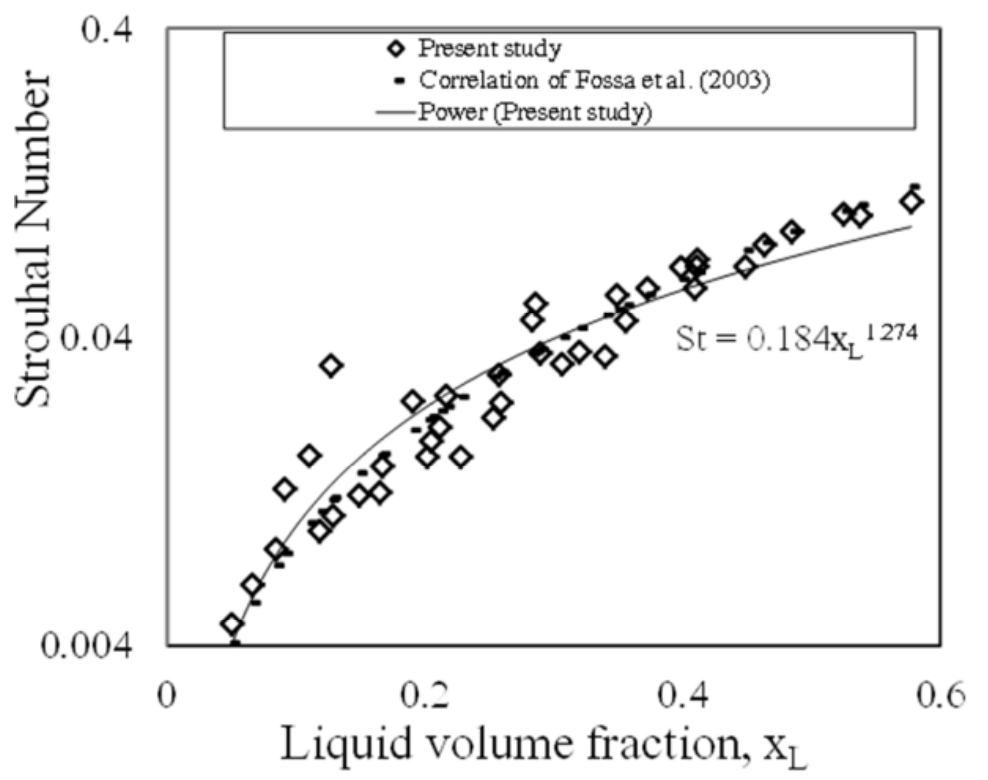

Figure 27: A logarithmic plot of the dimensionless Strouhal number versus the liquid volume fraction. A Comparison of the present experimental data is presented against the predictions derived from the correlation model proposed by [46].

A graphical representation of the experimentally established relationship between the Strouhal number and the Lockhart-Martinelli parameter is shown on the logarithmic plot given on Figure 28. The Lockhart-Martinelli parameter is defined according to equations (2728) as:

Lockhart-Martinelli parameter,

$X=\sqrt{\frac{\left(\frac{d p}{d x}\right)_{L}}{\left(\frac{d p}{d x}\right)_{G}}}=\sqrt{\frac{f_{L} \rho_{L} U_{S L}^{2}}{f_{G} \rho_{G} U_{S G}^{2}}}$

Where,

$f_{L}, f_{G}, \rho_{L}, \rho_{G},\left(\frac{d P}{d x}\right)_{L},\left(\frac{d P}{d x}\right)_{G}$ represent liquid and gas fugacities, liquid and gas densities and liquid and gas pressure gradients, respectively.

The high Reynolds number asymptote of $f$ is a constant. This constant is the same for both $G$ and $L$. Therefore $f_{g} / f_{L}=1$. 
Thus,

$$
X=\sqrt{\frac{\left(\frac{d p}{d x}\right)_{L}}{\left(\frac{d p}{d x}\right)_{G}}}=\sqrt{\frac{\rho_{L}}{\rho_{G}}} \frac{U_{S L}}{U_{S G}}
$$

Figure 28 illustrates a plot of the dimensionless Strouhal number St, defined as $\frac{f D}{U_{S G}}$ as a function of the Lockhart-Martinelli parameter as suggested by [27]. Also included on this plot, are experimental data from the present study, compared to data from previous similar experimental studies conducted in horizontal pipes of similar diameter. A comparison of these data sets confirms that the observed flow pattern is slug flow, where the frequency is made dimensionless by dividing by the gas superficial velocity. With the exception of the 50 mm pipe diameter, all of the other data sets may be shown to confirm a satisfactory linear fit with a positive gradient for all of the plotted experimental pipe diameter data sets.

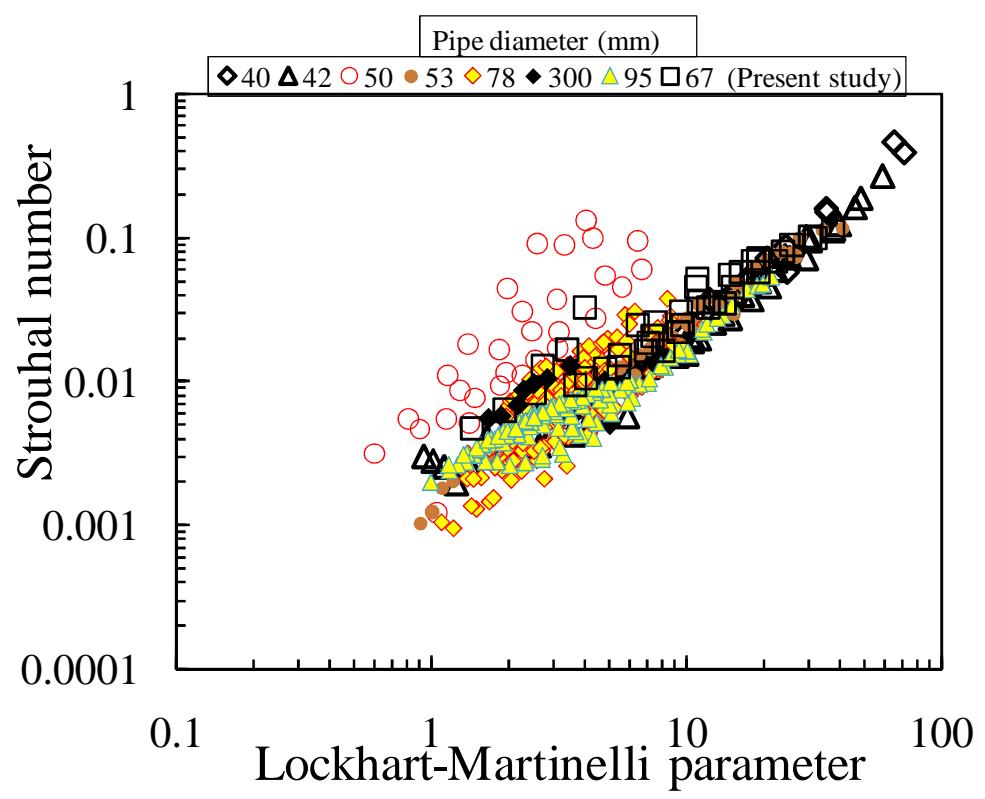

Figure 28: A plot of dimensionless frequency based on liquid superficial velocity against Lockhart-Martinelli parameter. $40 \mathrm{~mm}$ - [46]; $42 \mathrm{~mm}$ - [6]; $50 \mathrm{~mm}$ - [47]; 53 - [23]; $78 \mathrm{~mm}$ - [45]; 300 - [48]; $95 \mathrm{~mm}$ - [49] 


\section{Conclusions:}

The paper has presented an analysis and discussion of results of experiments conducted to characterise the slug flows produced within a horizontal $6 \mathrm{~m}$ long and $67 \mathrm{~mm}$ internal diameter pipeline when known quantities of air and silicone oil are injected at the inlet of the flowline. The flow characteristics were measured and characterised using non-intrusive instrumentation, including electrical capacitance tomography (ECT), wire mesh sensor (WMS) and differential pressure (dp) transducer cell. A summary of the main results are:

(1) The slug flow pattern is fully developed at 4,400 $\mathrm{mm}$ (64 pipe diameters) away from the mixing section based on a plot of slug frequency against axial distance, PDF of void fraction and a comparison between slug front and slug tail for the flow conditions considered.

(2) The experiments confirmed for horizontal slug flow, the existence of the expected linear dependence between the translational Taylor bubble velocity and the mixture superficial velocity. A good agreement was shown between the present experimental data trends with those predicted by the empirical relationships proposed by [7-8].

(3) It was found that for horizontal pipes the bubbles exhibit a drift velocity component that far exceeds the value found for vertical riser pipes.

(4) The frictional pressure gradient was observed to increase with liquid and gas superficial velocities.

(5) The average cross-sectional void fraction was observed to increase with an increase in gas superficial velocity.

(6) The void fraction in the liquid slug was found to be almost insensitive to both liquid and gas superficial velocities considered. A good agreement was concluded to exist between experimental void fraction observed in the liquid slug and those predicted by the correlation 
method of [11]. The void fractions in the Taylor bubble were confirmed to increase with an increase in the gas superficial velocity.

(7) No clear relationship was determined to characterize the slug unit in terms of the computed dimensionless slug length or other measured or computed variables. The observed slug lengths were of the order of 8 to 46 pipe diameters and relatively independent of flow conditions. However, the Taylor bubble lengths followed a near linear relationship with the corresponding measured slug unit lengths.

(8) The average slug length tends to decrease as the slug frequency increases, which confirms the findings of [19]. The ratio of average length of liquid slug to the average Taylor bubble length, $L_{S} / L_{T B}$, decreases as the gas superficial velocities increase and asymptotically approach zero at high gas flow rates.

(9) The length of the observed slug unit increases as the gas superficial velocity increases. However, at gas superficial velocity of $0.54 \mathrm{~ms}^{-1}$, the slug unit gets shorter with an increase in liquid superficial velocity. This confirms the observation reported by [19].

(10) The observed slug frequency increases with an increase in the liquid superficial velocity, whilst the computed dimensionless Strouhal number was found to increase with corresponding increases in the liquid volume fraction and Lockhart-Martinelli parameter. The observed frequency values were in good agreement with those predicted by the [46] empirical correlation, whose implicit empirical coefficients were computed from present experimental data. The slug frequencies predicted by the [26] correlation method gave closest agreement to the experimental data. 
This study has provided a more fundamental insight into the physical phenomena that govern the behaviour of slug flows in horizontal pipeline and the parameters that may be employed to characterize the slug flows generated under various flow conditions.

\section{ACKNOWLEDGEMENTS}

M. Abdulkadir would like to express sincere appreciation to the Nigerian government through the Petroleum Technology Development Fund (PTDF) for providing the funding for his doctoral studies.

This work has been undertaken within the Joint Project on Transient Multiphase Flows and Flow Assurance, sponsored by the UK Engineering and Physical Sciences Research Council (EPSRC); Advantica; BP Exploration; CD-adapco; Chevron; ConocoPhillips; ENI; ExxonMobil; FEESA; IFP; Institutt for Energiteknikk; Norsk Hydro; PDVSA (INTERVEP); Petrobras; PETRONAS; Scandpower PT; Shell; SINTEF; Statoil and TOTAL. The Authors wish to express their sincere gratitude for their supports.

\section{References}

[1] Bagci, S., 2003. An investigation of two-phase slug flow in inclined pipelines. Energy Sources, 26, 627638.

[2] Wang, X., Guo, L., Zhang, X., 2007. An experimental study of the statistical parameters of gas-liquid twophase slug flow in horizontal pipeline. International Journal of Heat and Mass Transfer, 50, 2439-2443.

[3] Hubbard M.G., Dukler A.E., 1966. The characterisation of flow regimes for horizontal two-phase flow. Proceedings of the 1966 Heat Transfer Fluid Mechanics Institute. Stanford University Press, Stanford, 385-400.

[4] Nicholson, K., Aziz, K., Gregory, G. A., 1978. Intermittent two phase flow in horizontal pipes, predictive models. Canadian Journal of Chemical Engineering, 56, 653-663.

[5] Gregory, G.A., Scott, D. S., 1969. Correlation of liquid slug velocity and frequency in horizontal concurrent as liquid flow, 15, 833-835.

[6] Heywood, N.I., Richardson, J. F., 1979. Slug flow of air-water mixtures in a horizontal pipe: determination of liquid holdup by gamma-ray absorption. Chemical Engineering Science, 34, 17.

[7] Weber, M.E., 1981. Drift in intermittent two-phase flow in horizontal pipes. The Canadian Journal of Chemical Engineering, 59, 398-399. 
[8] Bendiksen, K.H., 1984. An experimental investigation of the motion of long bubbles in inclined tubes. International Journal Multiphase Flow, 10, 467-483.

[9] Davies, R.M., Taylor, G., 1950. The mechanics of large bubbles rising through extended liquids and through liquids in tubes. Proceedings of the Royal Society of London, 200, 375-390.

[10] Benjamin, T.B., 1968. Gravity current and related phenomena. Journal of Fluid Mechanics, 31, part 2, 224.

[11] Gregory, G.A., Nicholson, M.K., Aziz, K., 1978. Correlation of the liquid volume fraction in the slug for horizontal gas-liquid slug flow. International Journal of Multiphase Flow, 4, 33-39.

[12] Marcano, R., T. X., Sarica, C., Brill, J. P., 1998. A Study of slug characteristics for two-phase horizontal flow. Society of Petroleum Engineers (SPE), 39856, 214.

[13] Gomez, L.E., Shoham, O., Taitel, Y., 2000. Prediction of slug liquid holdup: horizontal to upward vertical flow. International Journal of Multiphase Flow, 26, 517-521.

[14] Hubbard, M. G., 1965. An analysis of horizontal gas-liquid slug. PhD Thesis, University of Houston

[15] Abdulkadir, M., Hernandez-Perez, V., Lowndes, I.S., Azzopardi, B. J., Dzomeku, S., 2014a. Experimental study of the hydrodynamic behaviour of slug flow in a vertical riser. Chemical Engineering Science, 106, 6075 .

[16] Kouba, G. E., 1986. Dynamic calibration of two types of capacitance sensors used in measuring liquid holdup in two-phase. Proceedings of the $32^{\text {nd }}$ ISA International, Seattle.

[17] Gregory, G. A., Mattar, L., 1973. An in-situ volume fracture sensor for two-phase flows of nonelectrolytes. The Journal of Canadian Petroleum Technology, 12, 48-52.

[18] Malnes, D., 1983. Slug flow in vertical, horizontal and inclined pipes. IFE/KR/E-83/002 Institute for Energy Technology, Kjeller, Norway

[19] Hernandez-Perez, V., 2008. Gas-liquid two-phase flow in inclined pipes. PhD thesis, University of Nottingham.

[20] Barnea, D., Taitel, Y., 1993. A model for slug length distribution in gas-liquid slug flow. International Journal of Multiphase Flow, 19, 829-838.

[21] Dukler, A. E., Maron, D.M., Brauner, N., 1985. A physical model for predicting the minimum stable slug length. Chemical Engineering Science, 40, 1379.

[22] Taitel, Y., Dukler, A.E., 1977. A model for slug frequency during gas-liquid flow in horizontal and near horizontal pipes. International Journal of Multiphase Flow, 3, 585-596.

[23] Nydal, O.J., Pintus, S., Andreussi, P., 1991. Statistical characterization of slug flow in horizontal pipes. International Journal of Multiphase Flow, 18, 439-453.

[24] Greskovich, E.J., Shrier, A.L., 1972. Slug frequency in horizontal gas-liquid slug flow. Industrial Engineering Chemical Proceedings Design Development, 11, 317-318.

[25] Jepson, W. P., Taylor, R. E., 1993. Slug flow and its transitions in large-diameter horizontal pipes. International Journal of Multiphase Flow, 19, 411-420.

[26] Zabaras, G.J., 1999. Prediction of slug frequency for gas/liquid flows. Society of Petroleum Engineers (SPE), 5, 252-258. 
[27] Azzopardi, B. J., 1997. Drops in annular two-phase flow. International Journal of Multiphase Flow 23, S1S53.

[28] Geraci, G., Azzopardi, B. J., Van Maanen, H. R. E., 2007a. Inclination effects on circumferential film distribution in annular gas/liquid flows. AIChE Journal, 53, 1144-1150.

[29] Geraci, G., Azzopardi, B. J., Van Maanen, H. R. E., 2007b. Effects of inclination on circumferential film thickness variation in annular gas/liquid flows. Chemical Engineering Science, 62, 3032-3042.

[30] Khatib, Z., Richardson, J. F., 1984. Vertical co-current flow of air and shear thinning suspensions of kaolin. Chemical Engineering Research and Design, 62,139-154

[31] Costigan, G., Whalley, P. B., 1997. Slug flow regime identification from dynamic void fraction measurements in vertical air-water flows. International Journal of Multiphase Flow, 23, $263-282$.

[32] Shoham, O., 2006. Mechanistic modelling of gas-liquid two-phase flow in pipes, University of Tulsa, Society of Petroleum Engineers, USA.

[33] da Silva, M.J., Thiele, S., Abdulkareem, L., Azzopardi, B.J., Hampel, U., 2010, High-resolution gas-oil two-phase flow visualization with a capacitance wire-mesh sensor. Flow Measurement and Instrumentation, 21,191-197.

[34] Abdulkadir, M., Zhao, D., Azzi, A., L., Lowndes, I.S., Azzopardi, B. J., 2012. Two-phase air-water flow through a large diameter vertical $180^{\circ}$ return bend. Chemical Engineering Science, 79, 138-152.

[35] Govier, G.W., Radford, B. A., Dun, J.S.C., 1957. The upward flow of air-water mixture. I: Effect of air and water rates on flow pattern, holdup and pressure drop. Canadian Journal of Chemical Engineering, 35, 5870 .

[36] Weisman, J., Duncan, D., Gibson, J., Crawford, T., 1979. Effects of fluid properties and pipe diameter on two-phase flow patterns in horizontal lines. International Journal of Multiphase Flow, 5, 437-462.

[37] Woods, B.D., Hanratty, T.J., 2006. Frequency and development of slugs in a horizontal pipe at large liquid flows. International Journal of Multiphase Flow, 32, 902-925.

[38] Zheng, G. H., Brill, J.P., Shoham, O., 1994. Slug flow behaviour in a hilly terrain pipelines. International Journal of Multiphase Flow, 20, 63-79.

[39] Dukler, A. E., Hubbard, M.G., 1975. A physical model for gas - liquid slug flow in horizontal and near horizontal tubes. Industrial Engineering Chemical Fundamentals, 14, 337-347.

[40] Crowley, J.C., Sam, R.G., Wallis, G.B., 1984. Slug flow in a large diameter pipe. Paper presented at the AIChE A. Mtg, San Francisco, CA

[41] Beggs, H.D., Brill, J.P., 1973. A study of two-phase flow in inclined pipes. Transaction of Petroleum Society ASME, 256, 607-617.

[42] Barnea, D., Brauner, N., 1985. Holdup of liquid slug in two-phase intermittent flow. International Journal of Multiphase Flow, 11, 43-49.

[43] Ferre, D., 1981. Ecoulments gas-liquid a poches et a bouchons dans le conduits de section circulaire. These, Inst. National Polytechnic, Toulouse, France.

[44] Andreussi, P., Bendiksen, K., 1989. An investigation of void fraction in liquid slugs for horizontal and inclined gas-liquid pipe flow. International Journal of Multiphase Flow, 15, 937-946.

[45] Manolis, I.G., Mendes-Tatsis, M.A., Hewitt, G.F., 1990. The effect of pressure on slug frequency The effect of pressure on two-phase horizontal flow. Proceedings of the $2^{\text {nd }}$ International Conference on Multiphase Flow, Kyoto, 2, 1F1-35-40. 
[46] Fossa, M., Guglielmini, G., Marchitto, A., 2003. Intermittent flow parameters from void fraction analysis. Flow Measurement and Instrumentation, 14, 161-168.

[47] McNulty, J.G., 1987. Fluid property effects of Freon two-phase flow in a horizontal pipeline. Proceedings of the $2^{\text {nd }}$ International Conference on Multiphase Flow (BHRA Pub.), 149-160.

[48] Jepson, W. P., Taylor, R. E., Evans, N., 1989. Slug flow and its transitions in large-diameter horizontal pipes. UKAEA Report AERE, R 12992.

[49] Hill, T.J., Wood, D.G., 1990. A new approach to the predictions of slug frequency. SPE 20629. 65 ${ }^{\text {th }}$ Annual Technical Conference and Exhibition of the Society of Petroleum Engineers, New Orleans, September $23^{\text {rd }}-26^{\text {th }}, 141-149$.

[50] Ujang, P.M. , Lawrence, C.J. , Hale, C.P. , Hewitt, G. Slug initiation and evolution in two-phase horizontal flow, International journal of multiphase flow , Vol. 32, no 5 (May 2006), 527-552 
Figure captions:

Figure 1 A schematic diagram of the experimental riser rig inclined to be become a horizontal pipeline as shown in Figure 2. The physical measurements recorded on this rig were used to determine parameters that could subsequently be used to characterize the flow regime observed within the horizontal pipeline section when the flow rates of both the silicone oil and the air streams were varied.

Figure 2 Picture of the experimental rig in this study

Figure 3 Air-silicone oil mixing section

Figure 4 A typical PDF of void fraction. Liquid superficial velocity $=0.19 \mathrm{~ms}^{-1}$

Figure 5 Shoham [32]'s flow pattern map showing experimental data points. All experimental conditions lie in the slug flow region.

Figure 6 Comparison of average void fraction obtained from the ECT and WMS (a) Liquid superficial velocity $=0.14 \mathrm{~ms}^{-1}$ and gas superficial velocity $=0.05-4.73 \mathrm{~ms}^{-1}$ (b) Liquid superficial velocity $=0.28 \mathrm{~ms}^{-1}$ and gas superficial velocity $=0.05-4.73 \mathrm{~ms}^{-1}$ (c) Liquid superficial velocity $=0.38 \mathrm{~ms}^{-1}$ and gas superficial velocity $=$ $0.05-4.73 \mathrm{~ms}^{-1}$

Figure 7 Horizontal pipeline used in this study showing measurement locations

Figure 8 A plot of the average measured slug frequencies against the axial distance downstream of the gasliquid mixing section for the liquid superficial velocities $\left(\mathrm{ms}^{-1}\right)$ of: (a) 0.05 and (b) 0.38 .

Figure 9: Comparison between slug front and tail velocities at different gas and liquid superficial velocities.

Figure 10 A typical plot of the void fraction signals from the two ECT probes. The distance between the two ECT probes is $89 \mathrm{~mm}$. Liquid and gas superficial velocities are $0.05 \mathrm{~ms}^{-1}$ and $0.34 \mathrm{~ms}^{-1}$, respectively.

Figure 11 (a) Experimentally measured translational Taylor bubble velocity (structure velocity) as a function of mixture superficial velocity for the data corresponding to slug flow pattern. (b) Translational Taylor bubble velocity measured from experiment and empirical correlations. The empirical equations proposed by Weber [7] and Bendiksen [8] were recalculated using the physical properties of air and silicone oil.

Figure 12 Variation of the ratio of translational Taylor bubble velocity, $U_{T} / U_{M}$ with gas superficial velocity across a range of liquid superficial velocities

Figure 13 A plot of the frictional pressure gradient measured as the gas superficial velocity is increased for a range of increasing liquid superficial velocities.

Figure 14 The effect of gas superficial velocity on the average cross-sectional void fraction. The bars represent the standard deviation for all measurements made

Figure 15 The determined mean gas void fractions in the liquid slug

Figure 16 : Comparison between the experimental data and the considered empirical correlations 
Figure 17 The determined mean gas void fractions in the Taylor bubbles. Liquid superficial velocity $\left(\mathrm{ms}^{-1}\right)$ : $0.05-0.47$. The bars represent the standard deviation for all measurements made

Figure 18 Dependency of void fraction in the Taylor bubble on the void fraction in the liquid slug at different liquid superficial velocities.

Figure 19 Average length of liquid slug/length of Taylor bubble as a function of gas superficial velocity at different liquid superficial velocities

Figure 20 Illustrates a plot of the measured dimensionles average slug unit length against the gas superficial

velocity. These lengths were determined over an average experimental measurement period of 60 seconds.

Figure 21 A plot of the average dimensionless liquid slug length of the dimensionless slug unit length for a range of increasing liquid superficial velocities

Figure 22 A plot of the average dimensionless Taylor bubble length against the dimensionless slug unit length for a range of increasing liquid superficial velocities

Figure 23 A plot of the average liquid slug length as a function of slug frequency for a range of increasing liquid superficial velocities

Figure 24 A plot of the average slug frequency against the liquid superficial velocity for a range of increasing gas superficial velocities. Liquid superficial velocity $\left(\mathrm{ms}^{-1}\right)$ : $0.05-0.47$. The bars represent the standard deviation for all measurements made.

Figure 25 Plots of the variation of average slug frequency with gas superficial velocity using results obtained from experiments and empirical correlations for the following liquid superficial velocities $\left(\mathrm{ms}^{-1}\right)$ : (a) 0.05 (b) 0.095 (c) 0.14 (d) 0.19 (e) 0.24 (f) 0.38

Figure 26 A plot to compare the experimental data against the results of previously published empirical correlation models

Figure 27 A logarithmic plot of the dimensionless Strouhal number versus the liquid volume fraction. A Comparison of the present experimental data is presented against the predictions derived from the correlation model proposed by [46].

Figure 28 A plot of dimensionless frequency based on liquid superficial velocity against Lockhart-Martinelli parameter. $40 \mathrm{~mm}$ - [46]; $42 \mathrm{~mm}$ - [6]; $50 \mathrm{~mm}$ - [47]; 53 - [23]; $78 \mathrm{~mm}-$ [45]; $300-$ [48]; $95 \mathrm{~mm}-[49]$

Table captions:

Table 1 Summary of fully developed slug frequency models

Table 2 Properties of the fluids and dimensionless numbers at 1 bar and at the operating temperature of $20^{\circ} \mathrm{C}$

Table 3 Measurement uncertainties

Table 4 A plot of the PDF of void fraction measured at the three transducer locations along the length of the horizontal pipe downstream of the gas-liquid mixing section. 